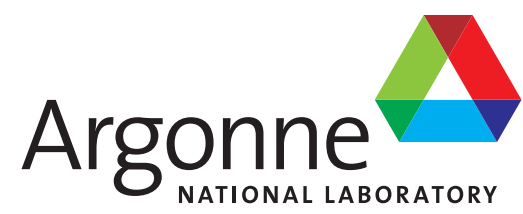

\begin{abstract}
A Spatially Explicit Individual-Based Modeling Approach to Evaluate the Cumulative Effects of Wind Energy Development on the Greater Sage-Grouse
\end{abstract}

Environmental Science Division 


\section{About Argonne National Laboratory}

Argonne is a U.S. Department of Energy laboratory managed by UChicago Argonne, LLC under contract DE-AC02-06CH11357. The Laboratory's main facility is outside Chicago, at 9700 South Cass Avenue, Argonne, Illinois 60439. For information about Argonne and its pioneering science and technology programs, see www.anl.gov.

\section{DOCUMENT AVAILABILITY}

Online Access: U.S. Department of Energy (DOE) reports produced after 1991 and a growing number of pre-1991 documents are available free at OSTI.GOV (http://www.osti.gov/), a service of the US Dept. of Energy's Office of Scientific and Technical Information.

Reports not in digital format may be purchased by the public from the National Technical Information Service (NTIS):

U.S. Department of Commerce

National Technical Information Service

5301 Shawnee Rd

Alexandria, VA 22312

www.ntis.gov

Phone: (800) 553-NTIS (6847) or (703) 605-6000

Fax: (703) 605-6900

Email: orders@ntis.gov

Reports not in digital format are available to DOE and DOE contractors from the Office of Scientific and Technical Information (OSTI):

U.S. Department of Energy

Office of Scientific and Technical Information

P.O. Box 62

Oak Ridge, TN 37831-0062

www.osti.gov

Phone: (865) 576-8401

Fax: (865) 576-5728

Email: reports@osti.gov

\section{Disclaimer}

This report was prepared as an account of work sponsored by an agency of the United States Government. Neither the United States Government nor any agency thereof, nor UChicago Argonne, LLC, nor any of their employees or officers, makes any warranty, express or implied, or assumes any legal liability or responsibility for the accuracy, completeness, or usefulness of any information, apparatus, product, or process disclosed, or represents that its use would not infringe privately owned rights. Reference herein to any specific commercial product, process, or service by trade name, trademark, manufacturer, or otherwise, does not necessarily constitute or imply its endorsement, recommendation, or favoring by the United States Government or any agency thereof. The views and opinions of document authors expressed herein do not necessarily state or reflect those of the United States Government or any agency thereof, Argonne National Laboratory, or UChicago Argonne, LLC. 


\section{A Spatially Explicit Individual-Based Modeling Approach to Evaluate the Cumulative Effects of Wind Energy Development on the Greater Sage-Grouse}

Final Report

prepared by

Kirk E. LaGory, Yuki Hamada, Paul F. Tarpey, Erica B. Levine, Cory C. Weber, Leroy J. Walston, and David J. LePoire

Environmental Science Division, Argonne National Laboratory

September 2012

Prepared for

Wind and Water Power Program

Energy Efficiency and Renewable Energy

U. S. Department of Energy

Washington, D.C. 



\section{CONTENTS}

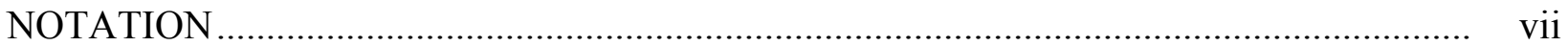

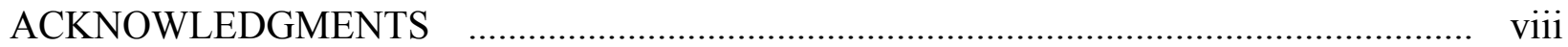

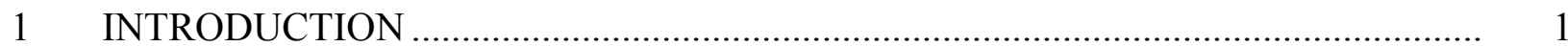

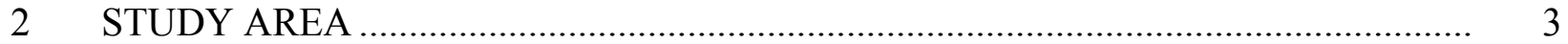

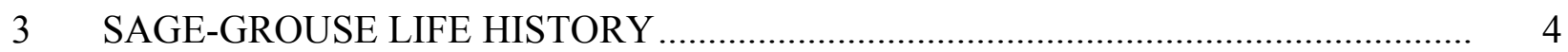

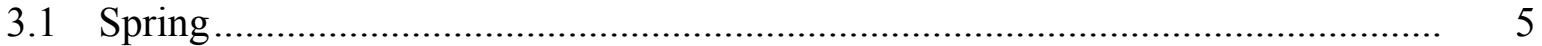

3.2 Summer and Autumn .............................................................................. 5

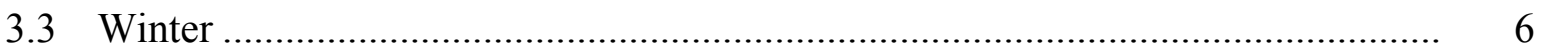

4 MODELING SAGE-GROUSE HABITAT SUITABILITY ………………….............. 6

4.1 Data Used For Modeling Habitat Suitability ………………………………….... 7

4.2 Habitat-Suitability Modeling Approach …………………………………….... 8

4.2.1 Nesting Habitat Suitability Model ........................................................... 8

4.2.2 Lekking Habitat Suitability Model ........................................................... $\quad 10$

4.2.3 Early Brood-Rearing Habitat Suitability Model ....................................... 11

4.2.4 Summer Habitat Suitability Model ............................................................ 12

4.2.5 Winter Habitat Suitability Model.............................................................. 13

4.3 Habitat Suitability Model Results ........................................................................ 14

4.4 Modeling the Impact of Wind Development and Associated Infrastructure .......... 18

$5 \quad$ MODELING INDIVIDUAL SAGE-GROUSE...................................................... 20

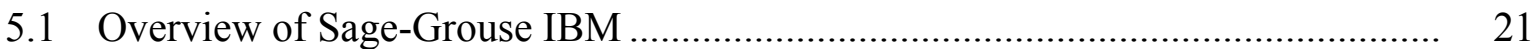

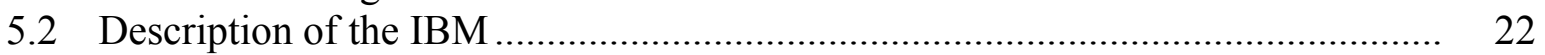

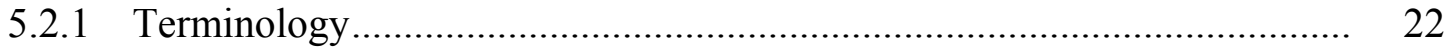

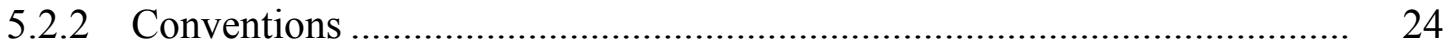

5.2.3 Modeled Objects and Related Functions ................................................ 24

5.2.3.1 Cells ............................................................................ 24

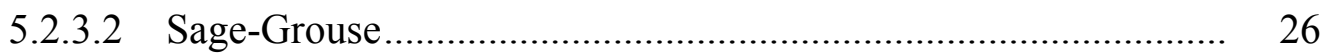

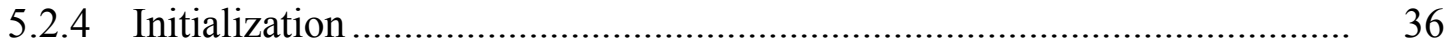

5.2.4.1 Cells ..................................................................... 36

5.2.4.2 Sage-Grouse..................................................................... 36

5.2.5 Scheduling................................................................................... 37

5.2.6 Model Output ................................................................................ $\quad 38$

6 INDIVIDUAL-BASED MODEL PERFORMANCE AND APPLICATION................. 40 


\section{CONTENTS (Cont.)}

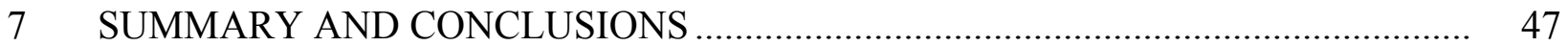

8 LIMITATIONS AND FUTURE STUDIES ............................................................ 48

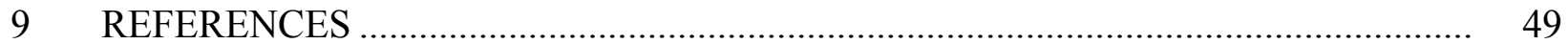

APPENDIX: Maps of Seasonal Sage-Grouse Distributions Projected under Baseline Conditions and Development Scenarios Before, During, and After Development

\section{TABLES}

1 Characteristics of Input Data Used in Habitat Suitability Models

2 Comparisons of Computed HSI Values Inside and Outside of Sage-Grouse Core Areas and Documented Lek Locations

3 Modeled Sage-Grouse Actions

4 Modeled Seasonal Habitats of Movements of Male and Female Sage-Grouse in Different Seasons

5 Modeled Maximum Travel Distances of Sage-Grouse between Seasons

6 Basis of Sage-Grouse Population Estimate for Albany County

\section{FIGURES}

$1 \quad$ Maps and Landscape of Albany County, Wyoming........................................................ 3

2 Conceptual Model of Sage-Grouse Life History ............................................................ 4

3 Model Used to Determine Sage-Grouse Nesting Habitat Suitability ............................ 9

$4 \quad$ Model Used to Determine Sage-Grouse Lekking Habitat Suitability .......................... 10

$5 \quad$ Model Used to Determine Sage-Grouse Early Brood-Rearing Habitat Suitability ...... 12 


\section{FIGURES (Cont.)}

6 Model Used to Determine Sage-Grouse Summer Habitat Suitability

7 Model Used to Determine Sage-Grouse Winter Habitat Suitability

8 Modeled Seasonal Sage-Grouse HSI Maps

9 Modeled Seasonal Sage-Grouse HSI Maps Compared to Published Information

10 Proportional Decrease in Sage-Grouse Survivorship in Relation to Distance from Infrastructure

11 Mapped Infrastructure Effects on Survivorship of Sage-Grouse Age Classes

12 Modeled Relationship between Sage-Grouse Condition and Nest Success

13 Modeled Relationship between Sage-Grouse Condition and Clutch Size.

14 Modeled Relationship between Sage-Grouse Condition and Length of Habitat Occupancy for a Sage-Grouse with a Starting Condition of 75 in a Seaonal Home Range with HSI Value of 60, 80, and 100 .

15 Modeled Relationship between Sage-Grouse Survivorship and Condition.

16 Scheduled Daily Actions of Individual Sage-Grouse in the IBM.

17 Modeled Seasonal Population Distributions under Baseline Conditions after Initialization and in Three Subsequent Years

18 Modeled Number of Adult and Yearling Sage-Grouse under Baseline Conditions by Year and Season

19 Hypothetical Wind Development Scenarios Evaluated with the IBM

20 Modeled Spatial Distributions and Population Trajectories of Sage-Grouse under Baseline Conditions and Three Hypothetical Development Scenarios

21 Modeled Number of Adult and Yearling Sage-Grouse under Three Hypothetical Development Scenarios over 5 Years

A-1 Modeled Spatial Distribution of Sage-Grouse Population in Winter under Baseline Condition and Three Hypothetical Development Scenarios over 5 Years 


\section{FIGURES (Cont.)}

A-2 Modeled Spatial Distribution of Sage-Grouse Population in Spring under Baseline Condition and Three Hypothetical Development Scenarios over 5 Years

A-3 Modeled Spatial Distribution of Sage-Grouse Population in Summer under Baseline Condition and Three Hypothetical Development Scenarios over 5 Years .................... 


\section{NOTATION}

The following is a list of the acronyms, initialisms, and abbreviations (including units of measure) used in this document.

\section{ACRONYMS, INITIALISMS, AND ABBREVIATIONS}

$\begin{array}{ll}\text { BLM } & \text { Bureau of Land Management } \\ \text { CART } & \text { Classification and Regression Tree } \\ \text { DEM } & \text { Digital Elevation Model } \\ \text { DOE } & \text { U.S. Department of Energy } \\ \text { ETM+ } & \text { Enhanced Thematic Mapper Plus } \\ \text { GNN } & \text { Gradient Nearest Neighbor } \\ \text { HSI } & \text { Habitat Suitability Index } \\ \text { IBM } & \text { Individual-Based Model } \\ \text { NWGAP } & \text { Northwest Gap Analysis Program } \\ \text { USFWS } & \text { U.S. Fish and Wildlife Services } \\ \text { USGS } & \text { U.S. Geological Survey }\end{array}$

\section{UNITS OF MEASURE}

$\begin{array}{ll}\mathrm{cm} & \text { centimeter(s) } \\ \mathrm{km} & \text { kilometer(s) } \\ \mathrm{m} & \text { meter(s) }\end{array}$




\section{ACKNOWLEDGMENTS}

We thank Patrick Gilman and Jim Ahlgrimm of the U.S. Department of Energy for providing support and direction for this work as well as helpful comments on an earlier draft. We also thank Jocelyn Brown-Saracino and Raphael Tisch of New West Technologies for their review and constructive input, and Lauren Flinn of the American Wind Wildlife Institute for coordinating interactions with the Sage-Grouse Collaborative. Tim Novotny of the Bureau of Land Management provided information on known sagegrouse lek sites in Wyoming. This work was funded by the Wind and Water Power Program, Energy Efficiency and Renewable Energy, U.S. Department of Energy under contract DE-AC02-06CH11357. 


\title{
A SPATIALLY EXPLICIT INDIVIDUAL-BASED MODELING APPROACH TO EVALUATE THE CUMULATIVE EFFECTS OF WIND ENERGY DEVELOPMENT ON THE GREATER SAGE-GROUSE
}

\author{
Kirk E. LaGory, Yuki Hamada, Paul F. Tarpey, Erica B. Levine, \\ Cory C. Weber, Leroy J. Walston, and David J. LePoire \\ Environmental Science Division \\ Argonne National Laboratory
}

\section{INTRODUCTION}

In order to achieve the national vision of $20 \%$ of energy being produced by wind by 2030 , issues associated with wind energy development's potential impacts on ecological resources must be addressed. In particular, wind energy and associated transmission system development may affect wildlife populations through direct mortality, habitat fragmentation, habitat degradation, and disturbance. Although individual projects may have little effect on the sustainability of wildlife populations, cumulative impacts could be significant. The wind energy industry and regulators have developed processes for assessing the impacts of individual projects and identifying mitigation requirements, but no one has developed a methodology for considering cumulative impacts in a systematic and holistic way.

The goal of the project described in this report was to develop a landscape-based modeling framework that considered the cumulative impacts of prospective wind energy development in the western United States on populations of critically important wildlife species in order to facilitate smart development that minimizes ecological impact. Project objectives included development of a prototype modeling framework for the greater sage-grouse (Centrocercus urophasianus) to demonstrate the viability of the technical approach, its applicability to evaluating the cumulative effects of wind energy development, and the issues associated with full-scale deployment of the model. The model would be able to examine population viability over an extended time frame (e.g., decades or centuries) by using realistic starting populations and spatial distributions. This model is intended to assist the Department of Energy's (DOE's) Energy Efficiency and Renewable Energy Program, wind energy developers, and permitting authorities in planning for dispersed but potentially extensive development in critically important wildlife areas.

We chose the greater sage-grouse to demonstrate the viability of the technical approach, its applicability to evaluating the cumulative effects of wind energy development, and the issues associated with broader use of the framework because of its occurrence in areas of high wind potential and its possible sensitivity to development impacts. Additional species or species complexes (e.g., waterfowl) could be considered for future adaptations of our approach. 
The greater sage-grouse is a gallinaceous bird whose historic range extends throughout parts of 12 U.S. states (Washington, Oregon, California, Idaho, Nevada, Utah, Montana, Wyoming, Colorado, Nebraska, South Dakota, and North Dakota) and three Canadian provinces (Alberta, British Colombia, and Saskatchewan) (Aldridge and Boyce 2007; Schroeder et al. 2004). The greater sage-grouse relies on sagebrush (Artemisia spp.) for shelter and food, and is one of many sagebrush-obligate species (i.e., species whose continued existence is dependent on sagebrush-dominated habitats). The species' distribution is closely associated with that of shrubsteppe ecosystems. The conversion of these ecosystems to non-shrublands has resulted in a significant reduction in sage-grouse populations, and the species now occupies only about $56 \%$ of its historical range (Aldridge et al. 2008; Connelly et al. 2004). Because of this significant population decline, the sage-grouse is currently a candidate for listing under the Endangered Species Act.

The greater sage-grouse has an unusual, complex life history, including characteristic mating rituals and movements between seasonal ranges (Connelly et al. 2004). The species shows strong site fidelity through its life cycle and returns annually to seasonal habitats including traditional strutting grounds (called leks) where males perform courtship displays. Disruption of any portion of the annual life cycle could result in long-term impacts in a wider portion of the species range.

The sage-grouse holds ecological importance as an indicator species of sagebrush ecosystem health, as well as cultural value for its fascinating mating rituals. Therefore, the species' significant population decline (Naugle et al. 2004), particularly due to habitat loss and degradation from energy development (Doherty et al. 2010a), is of great concern. Although most of this development has been for the production of oil and gas, concern extends to any development, including wind energy facilities. Increasing concerns over the sustainability of sage-grouse populations in the face of increasing development have led to restrictions on development in sage-grouse core areas. Incomplete understanding of the bird's response to the development of wind farms and other structures could lead to unnecessary or ineffective restrictions. Therefore, there is a need for developing a tool to estimate the effects of habitat loss and degradation on population viability through the identification of critical elements of the species' life history and habitat usage that are most susceptible to wind energy development.

We followed five steps in developing our modeling framework: (1) develop a conceptual model of the life history of the sage-grouse, (2) develop seasonal habitat suitability indices, (3) determine infrastructure effects on survivorship and habitat suitability, (4) develop and test an individual-based model (IBM) of sage-grouse based on these three elements, and (5) use the model to evaluate the effects of hypothetical wind energy development scenarios on sage-grouse in our study area. 


\section{STUDY AREA}

Our model was developed for a limited geographic area to support a proof-of-concept demonstration. We chose Albany County, Wyoming, as the area of focus (Figure 1) because the county has high wind energy potential and currently supports a large number of sage-grouse. The area is located near the southeastern corner of the state and covers approximately $11,000 \mathrm{~km}^{2}$. According to the National Renewable Energy Laboratory (NREL 2009), more than 30\% of the land in Albany County exhibits high wind energy potential (i.e., Class 5 or above). At least a portion of the county supports a high-density sage-grouse population (Doherty et al. 2010a).

Vegetation associations of Albany County consist of sagebrush-dominated shrubland/steppe and mixed grassland. Sagebrush communities containing big sagebrush (Artemisia tridentata tridentata) and Wyoming sagebrush (A. t. wyomingensis) provide important habitats for the greater sage-grouse. Areas of lower elevation are characterized by a gradient of dry to wet mixed-grass prairie with a few major riparian/wetland vegetation communities and croplands. The central portion of the study area exhibits a mosaic of sagebrush and mesic grassland habitats. Higher elevations in the county are dominated by woodlands and forests. Elevation within the study area ranges from 1,500 to 3,600 m.
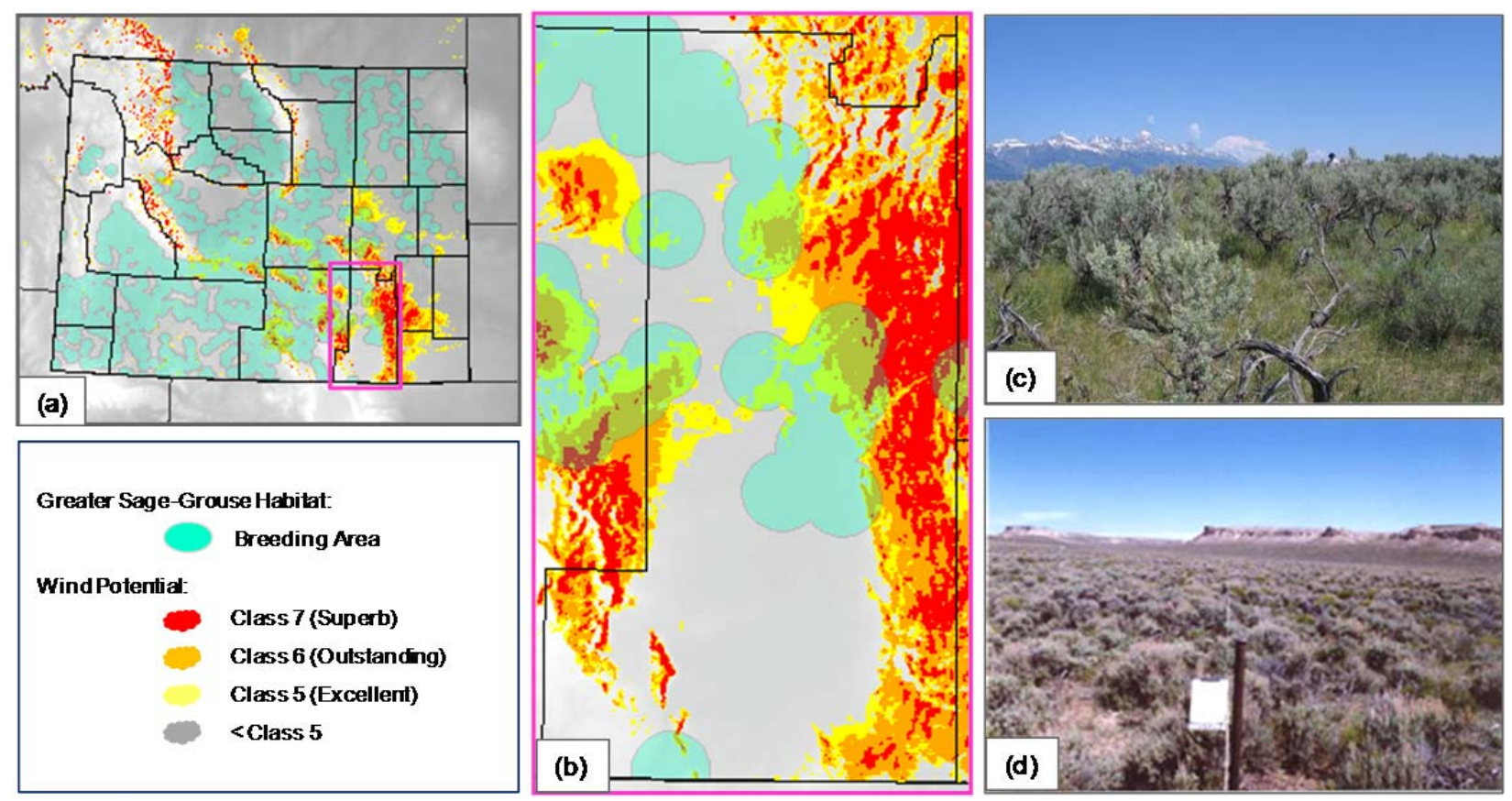

FIGURE 1 Maps and Landscape of Albany County, Wyoming: (a) state of Wyoming showing sagegrouse breeding areas and wind potential; (b) close-up of the Albany County study area; and (c) and (d) sagebrush habitats (USGS 2007; Wyoming Interagency Vegetation Committee 2002) 


\section{SAGE-GROUSE LIFE HISTORY}

Sage-grouse life history stages and processes, as described in the literature, formed the basis for our IBM framework. We extracted information on movements between seasons, breeding behavior (e.g., lekking and nesting), chick production and growth, brood rearing, age- and sex-specific behaviors, and seasonal, age, and sex differences in survivorship. We recognized four age classes: chick (0-10 weeks), juvenile (11-40 weeks), yearling (41-103 weeks), and adult ( $\geq 104$ weeks). These age classes are based on information in Beck et al. (2006). Sage-grouse chicks and juveniles follow their mothers; the behavior of yearlings is very similar to that of adults.

A generalized conceptual model of sage-grouse life-history is presented in Figure 2. This figure shows movements between seasonal habitats and the important activities that occur in those habitats. Three seasons are shown: spring (March-early June, representing the breeding season when lekking, mating, nesting, and brood rearing occur), summer (June-mid-September), and winter (December-late February). Autumn (mid-September-December) is a transitional period when sage-grouse move from summer to winter habitat. Males and females differ in their use of seasonal habitats, as described in the remainder of this section.

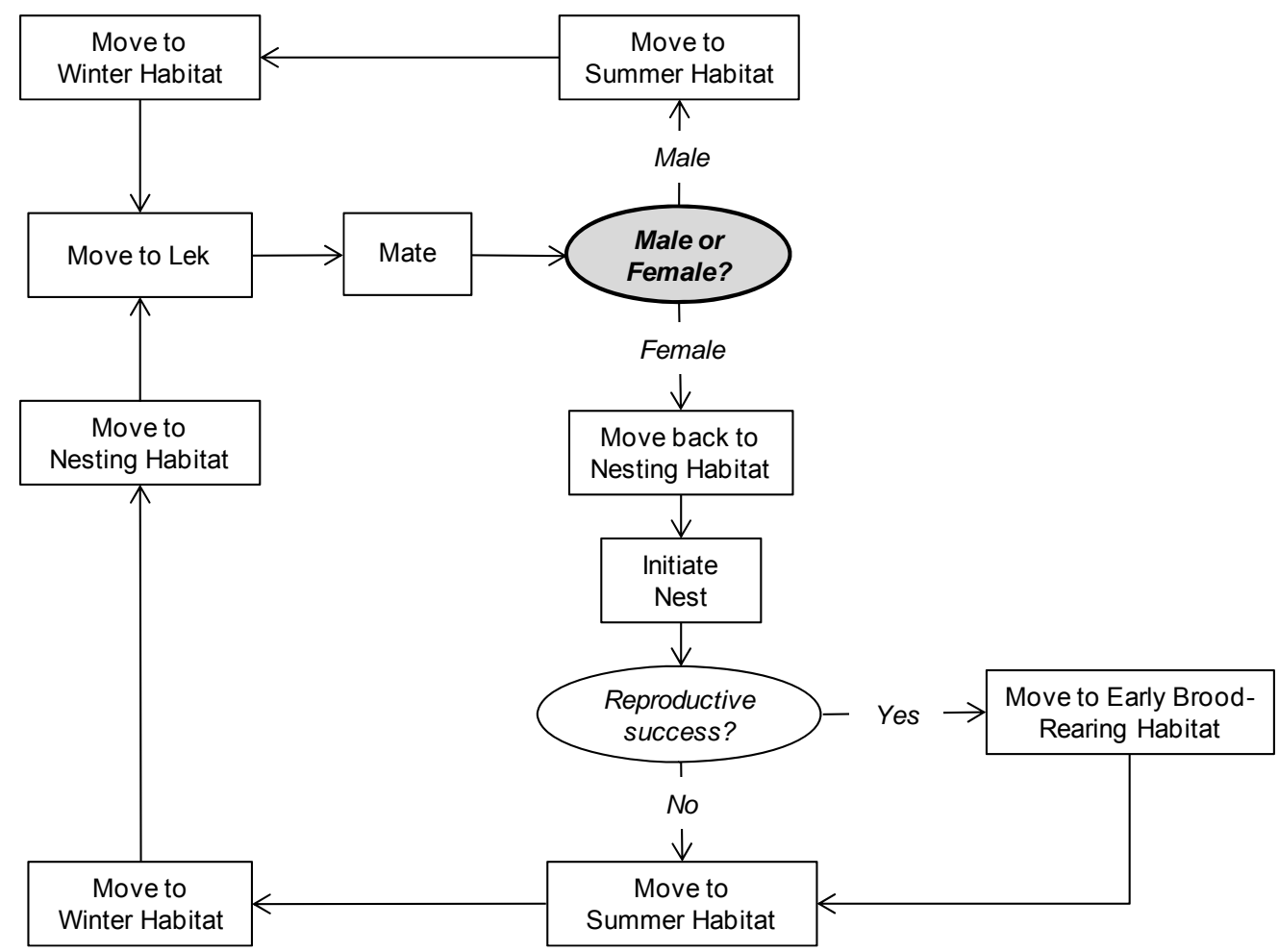

FIGURE 2 Conceptual Model of Sage-Grouse Life History (Chicks and juveniles follow their mother until becoming yearlings.) 


\subsection{SPRING}

Male sage-grouse occupy sparsely vegetated communal strutting grounds (known as leks) and display to females for mating from mid-March (or as early as snowmelt) to May (Connelly et al. 2004). Leks are commonly located within areas of high female traffic in good nesting habitat (Bradbury et al. 1989). Multiple males perform elaborate rituals at the same site for a few hours each day over a 3-month period (Schroeder et al. 1999).

Female sage-grouse select nest sites 1 to 2 weeks prior to attending leks (Bradbury et al. 1989). Females typically nest in sagebrush habitats containing native herbs from April to early June, often within $5 \mathrm{~km}$ of the lek on which they mated (Holloran and Anderson 2005). Females visit leks 7 to 10 days after males establish lek territories (Schroeder et al. 1999). The peak in female lek attendance occurs in early to mid-April (Connelly et al. 2004; Schroeder et al. 1999). Females move directly from leks to nests after mating. Females lay their first eggs 3 to 14 days after copulation and continue to lay eggs at a rate of 2 eggs every 3 days (Schroeder et al. 1999). Clutch size ranges from 5 to 9 eggs and averages 7.4 eggs in Wyoming, with adults laying 0.2 to 2.1 more eggs than yearlings (Connelly et al. 2004; Schroeder et al. 1999). Incubation occurs over a 25- to 29-day period until eggs hatch (Schroeder et al. 1999). Reproductive success varies, and adult nest success is 18\% higher than yearling nest success (Holloran 1999). Reproductive success is positively correlated with distance from lek, as well as April-June precipitation, and vegetation characteristics of the site (Holloran and Anderson 2005; Schroeder et al. 1999). Females that are unsuccessful in producing chicks migrate directly to summer habitat after nest failure, and arrive shortly after males (Connelly et al. 2004).

Females rear their broods in areas within sagebrush-dominated habitats with abundant forbs (Holloran 1999; Crawford et al. 2004; Sage-Grouse Working Group 2003). Early broodrearing habitats are typically located within $2.4 \mathrm{~km}$ of nests. Home range size from June to midJuly is generally 0.1 to $5 \mathrm{~km}^{2}$ (Sage-Grouse Working Group 2003; Crawford et al. 2004). Chicks feed 1 to $10 \mathrm{~m}$ from mothers (Schroeder et al. 1999).

\subsection{SUMMER AND AUTUMN}

In summer, as vegetation in spring habitats dries out, sage-grouse move to mesic habitats such as riparian areas, irrigated alfalfa fields, upland meadows, and greasewood (Sarcobatus vermiculatus) bottoms (Wallestad 1971; Wambolt et al. 2002). Although they appear to prefer sagebrush-dominated habitats, females with broods select summer habitat primarily based on the availability of food and use open riparian habitat if more mesic sagebrush microsites are unavailable (Holloran 1999). Both males and females occupy the same habitat and are found in close proximity throughout the summer (Holloran 1999). Summer home ranges vary in size from 0.1 to $25.9 \mathrm{~km}^{2}$ (Schroeder et al. 1999). Grouse density can be very high in summer, increasing their susceptibility to disease (Connelly et al. 2004) and predators. In late summer and early fall, females and their young begin to disassociate and juveniles form large flocks. 
Habitats used by sage-grouse in autumn are transitional in nature (i.e., sage-grouse use those habitats that are crossed as the birds move from summer to winter habitat) and can differ greatly by elevation, topography, weather, and availability (Connelly et al. 2004). The distance moved between summer and winter range varies widely. Sage-grouse usually move along traditional routes and follow topographical features as they move between seasonal habitats, avoiding steep slopes and areas without sagebrush cover, although some birds may cross areas lacking cover (Dunn and Braun 1986). The timing of migration is dependent on weather, including cold temperatures, first frost, and first snowfall. Movement to winter habitat is generally completed before significant snow accumulation (Schroeder et al. 1999; Berry and Eng 1985).

\subsection{WINTER}

Winter habitat consists of large, uninterrupted expanses of dense sagebrush (Eng and Schladweiler 1972). Grouse location within winter range depends on sagebrush availability, which in turn varies with snow depth, topography, and vegetation height (Connelly et al. 2004). Sage-grouse typically occupy lower elevations at the beginning of winter (Connelly et al. 2004). Grouse forage on windswept ridges and on south- and west-facing slopes (Sage-Grouse Working Group 2003; Doherty et al. 2006). They avoid rugged terrain, riparian areas, conifer forest, and edge habitats (Doherty et al. 2006). Sage-grouse movements within winter habitat are triggered by snowfall as grouse seek areas with available sagebrush 25 to $35 \mathrm{~cm}$ above the snow (Bohn et al. 2007). Movements between these distinct roosting and foraging sites may exceed $8 \mathrm{~km}$ in distance and $300 \mathrm{~m}$ in elevation (Sage-Grouse Working Group 2003). By first snowfall, sage-grouse form loose associations of 50 to 300 individuals (Dalke et al. 1963).

\section{MODELING SAGE-GROUSE HABITAT SUITABILITY}

We developed habitat suitability models for five stages of sage-grouse life history (lekking, nesting, early brood-rearing, summer, and winter) using geospatial data of environmental variables in conjunction with published studies of the species' habitat usage. We used these habitat suitability models to generate habitat suitability index (HSI) maps. The HSI maps characterized the landscape of the study area in our IBM and served as the basis for habitat selection, sage-grouse condition, reproduction, and survivorship. The U.S. Geological Survey (USGS) and others have been developing sage-grouse habitat suitability models based on detailed studies of habitat use and movement patterns. These completed habitat suitability models were not available when we started our project, and are not expected to be available until sometime in 2012. As a consequence, we developed our own habitat suitability models to serve as the habitat information for our IBM. The data we used and our process for developing these habitat suitability models are presented in the remainder of this section. 


\subsection{DATA USED FOR MODELING HABITAT SUITABILITY}

Data we utilized for modeling habitat suitability and infrastructure effects on sage-grouse and developing wind development scenarios are shown in Table 1. Fractional cover maps of sagebrush, herbaceous plants, and soil were derived based on rigorous models using Landsat Enhanced Thematic Mapper Plus (ETM+) and QuickBird multispectral imagery and field measurements (Homer et al. 2008). The sagebrush-cover map represents percent ground cover of sagebrush species (Artemisia tridentata) that include big sagebrush and Wyoming sagebrush. The herbaceous cover map includes both grasses and forbs. The shrub height map represents the height of all shrub species. All these maps have $30 \mathrm{~m}$ spatial resolution. These geospatial data layers were utilized to characterize vegetation structure of sage-grouse habitats.

TABLE 1 Characteristics of Input Data Used in Habitat Suitability Models

\begin{tabular}{llll}
\hline \multicolumn{1}{c}{ Data Category } & \multicolumn{1}{c}{ Variable } & Data Type & \multicolumn{1}{c}{ Source } \\
\hline & Sagebrush & $30 \mathrm{~m}$, continuous & Homer et al. (2008) \\
$\begin{array}{l}\text { Vegetation height } \\
\text { Fractional cover }\end{array}$ & Herb & $30 \mathrm{~m}$, continuous & Homer et al. (2008) \\
& Soil & & \\
& Sagebrush & $30 \mathrm{~m}$, continuous & USGS (2009) \\
Digital Elevation Model & Elevation & $30 \mathrm{~m}$, categorical & NWGAP (2010) \\
Land cover type & Vegetation type & Non-geospatial & Novotny (2010) \\
Field observation & Lek location, male attendance & & \\
\hline
\end{tabular}

We used a Digital Elevation Model (DEM) with a $30 \mathrm{~m}$ resolution to characterize the topography of habitats. We generated slope values (in percent) and aspects (in degree) from the DEM. These two topographic layers provided important information, particularly for sage-grouse winter habitats.

The Northwest Gap Analysis Program (NWGAP) land cover map depicts distributions of over 200 ecosystems and land cover types that include 31 shrub habitat types of the northwestern United States (Gap Analysis Program 2010). We used the land cover map to generate multiple models including Gradient Nearest Neighbor (GNN; Ohmann and Gregory 2002) and Classification and Regression Tree (CART) in conjunction with multi-seasonal satellite imagery. We also used information from the NWGAP on vegetation association and species occurrence, which supplemented the data on vegetation height and fractional cover from Homer et al. (2008), to guide habitat suitability modeling.

The locations and attendance of males at over 2,000 leks in the state of Wyoming were recorded by the Bureau of Land Management (BLM) between 1948 and 2009. We converted the field data to a geospatial layer in order to evaluate our lek HSI map.

Once we had completed all data preprocessing, we subsetted (i.e., clipped) datasets to a common extent prior to modeling. 


\subsection{HABITAT SUITABILITY MODELING APPROACH}

We gathered information about the characteristics of suitable habitat for each stage of the greater sage-grouse's life history by conducting an extensive literature review. We evaluated peer-reviewed journal articles, habitat assessment reports, conference proceedings, and book chapters, the majority of which are based on field observations that range from site-specific studies to multi-state, range-wide projects.

For each life-history stage, we identified the key components that define a suitable habitat, such as food and shelter. The number and type of components varied depending on lifehistory stage. From published studies, we identified the important features of each component (e.g., vegetation type, shrub height, and slope), and the desired characteristics and patterns of each feature such as presence/absence of certain plant species, the amount of cover or height of plant life forms, and adjacency to vegetation types.

In general, there was insufficient information in existing studies to determine relationships among variables and habitat suitability or relative contributions between variables/components. Therefore, for simplicity, we developed piecewise linear functions of suitability based on the assumption that all variables are of equal weight and applied these functions to geospatial layers to generate indices ranging from 0 (poor) to 100 (optimal). This approach is similar to that used for many of the U.S. Fish and Wildlife Service (USFWS) Habitat Suitability Index models in their Habitat Evaluation Procedure, (available at http://www.fws.gov/policy/ESMindex.html).

If appropriate data were not available, we estimated values from surrogate data. In some cases, we used one or more "component" indices (e.g., sagebrush cover index and grass index) to compute an index (e.g., shelter index and food index) that represents the key habitat characteristic upon which the HSI was determined. To integrate multiple component indices to compute an index, we calculated the geometric mean of the component indices unless a wellestablished relationship was known.

Once each seasonal HSI map was generated, we applied a spatial average filter to the map to obtain average suitability within the range for a given individual. The HSI value of a given pixel in the average HSI map represents overall suitability of the seasonal range that surrounds that pixel if that pixel is the center of the seasonal home range. We then spatially aggregated the map data to create a $240-\mathrm{m}$ resolution map that would improve the computational efficiency of our IBM.

\subsubsection{Nesting Habitat Suitability Model}

We developed a habitat suitability model of nesting habitats based on food availability and shelter quality (Figure 3). The abundance of herbaceous vegetation, particularly native grasses and forbs, is an important determinant of food availability during the nesting season. Specific sage-grouse food items are well documented (Connelly et al. 2004; Holloran 1999; 


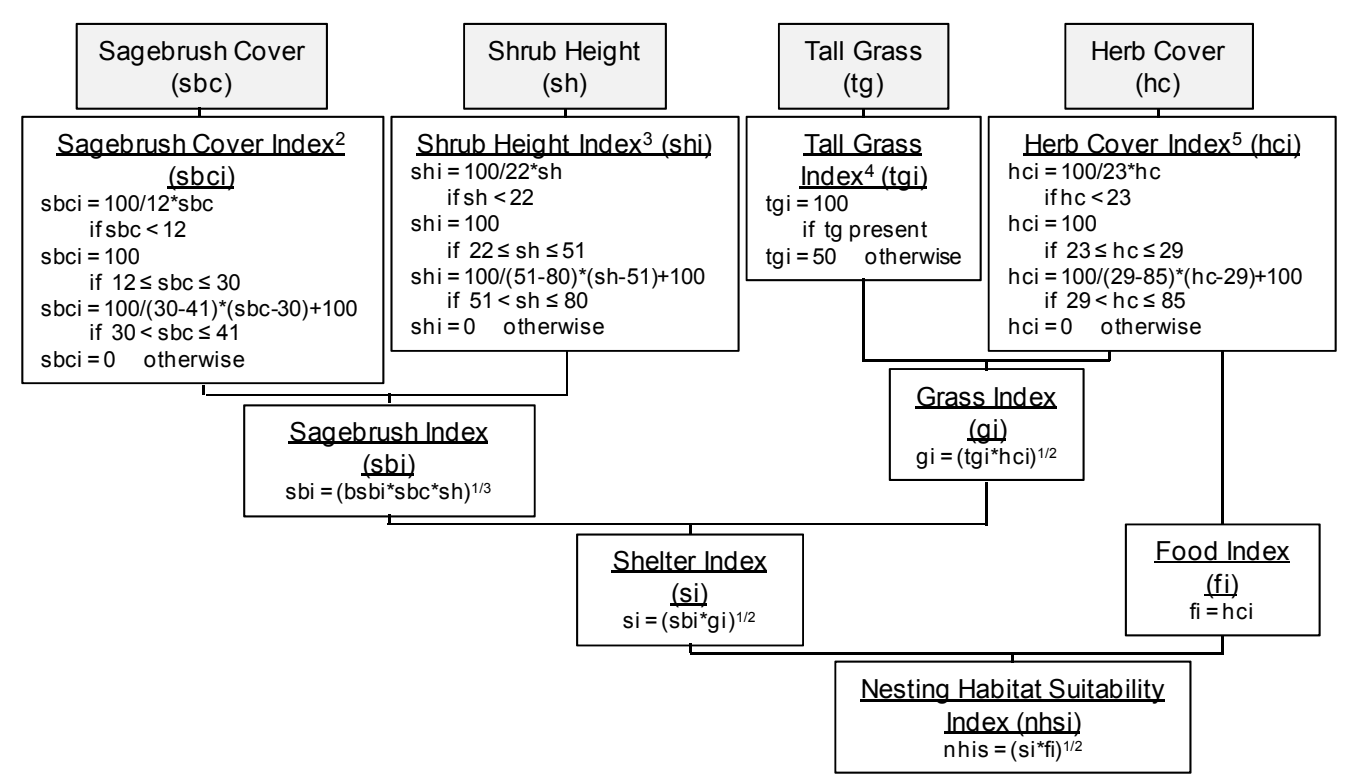

FIGURE 3 Model Used to Determine Sage-Grouse Nesting Habitat Suitability

Wallestad and Eng 1975). We characterized food availability based on the overall cover fraction of herbaceous plants, which includes both grasses and forbs, using the herb fractional cover map (Table 1) because of the lack of geospatial data that differentiated between native and nonnative herbs or identified major species. For the herb cover index, we identified an optimal range between 23\% and 29\% (Connelly et al. 2004; Holloran et al. 2005; Figure 3), and a maximum value of $85 \%$ (Sage-Grouse Working Group 2003). For herb cover fractions below $23 \%$ or between $29 \%$ and $85 \%$, the index value increased from 0 to 100 or decreased from 100 to 0 linearly with cover fraction, respectively. We assigned an index value of 0 if herb cover was greater than $85 \%$.

We determined the shelter component for nesting habitat based on the following three factors: sagebrush cover, shrub height, and grass height. We first computed indices of sagebrush cover and shrub height to characterize shrubs within the habitat using maps of sagebrush cover fraction and shrub height (Table 1).

For the sagebrush cover index, we set the range of optimal sagebrush cover between $12 \%$ and 30\% (Connelly et al. 2004; Figure 3), and the maximum cover at 41\% (Gregg et al. 1994). For sagebrush cover fractions below $12 \%$ or between $30 \%$ and $41 \%$, the index value increased from 0 to 100 or decreased from 100 to 0 linearly with cover fraction, respectively. We assigned an index value of 0 if sagebrush cover was greater than $41 \%$.

For the shrub height index, we used a range of optimal height between $22 \mathrm{~cm}$ and $51 \mathrm{~cm}$ based on information in Connelly et al. (2004), and a maximum shrub height of $80 \mathrm{~cm}$ based on information in Gregg et al. (1994). For shrub heights below $22 \mathrm{~cm}$ or between $51 \mathrm{~cm}$ and $80 \mathrm{~cm}$, the index value increased from 0 to 100 or decreased from 100 to 0 linearly with height, respectively. We assigned an index value of 0 to shrub height values greater than $80 \mathrm{~cm}$. We 
used the sagebrush cover index and shrub height index to compute the sagebrush index (Figure 3).

Because we did not have geospatial data for grass height, we used data on the occurrence of grasses and forbs from the NWGAP land cover map as a surrogate measure to determine the value for our grass index. Using the NWGAP land cover map (Table 1), we assigned a value of 100 to habitats containing tall grass species and a value of 50 to all others. We then used the tall grass index and the herb cover index to calculate the grass index (Figure 3). We computed the shelter index by integrating the grass index and the sagebrush index (Figure 3). Finally, we used the shelter and food indices to calculate the nesting HSI value of each pixel (Figure 3), and applied a $1 \mathrm{~km}^{2}$ average filter (representing a typical nesting habitat range) to produce the nesting HSI map.

We performed both qualitative and quantitative assessments to examine the level of agreement between our nesting HSI map and the map of greater sage-grouse core areas (WGFD 2010). We sampled nesting HSI values at 150 randomly selected pixels from within core areas and outside core areas. We computed summary statistics of these two samples and performed a t-test to determine the significance of HSI values between sample values inside and outside of core areas.

\subsubsection{Lekking Habitat Suitability Model}

We developed a habitat suitability model of lekking habitats using four components: food, shelter, open space, and nest proximity (nesting HSI). We computed the open-space index using the bare ground fraction map (Table 1). The minimum fraction of bare ground was set at $10 \%$ (Figure 4). Areas with bare ground $10 \%$ or less were not considered suitable for lekking (open-space index $=0$ ), but areas with more than $10 \%$ open space were considered optimal for lekking and given an open-space index value of 100. The nesting HSI map was used to represent potential occurrence of nests in surrounding environments.

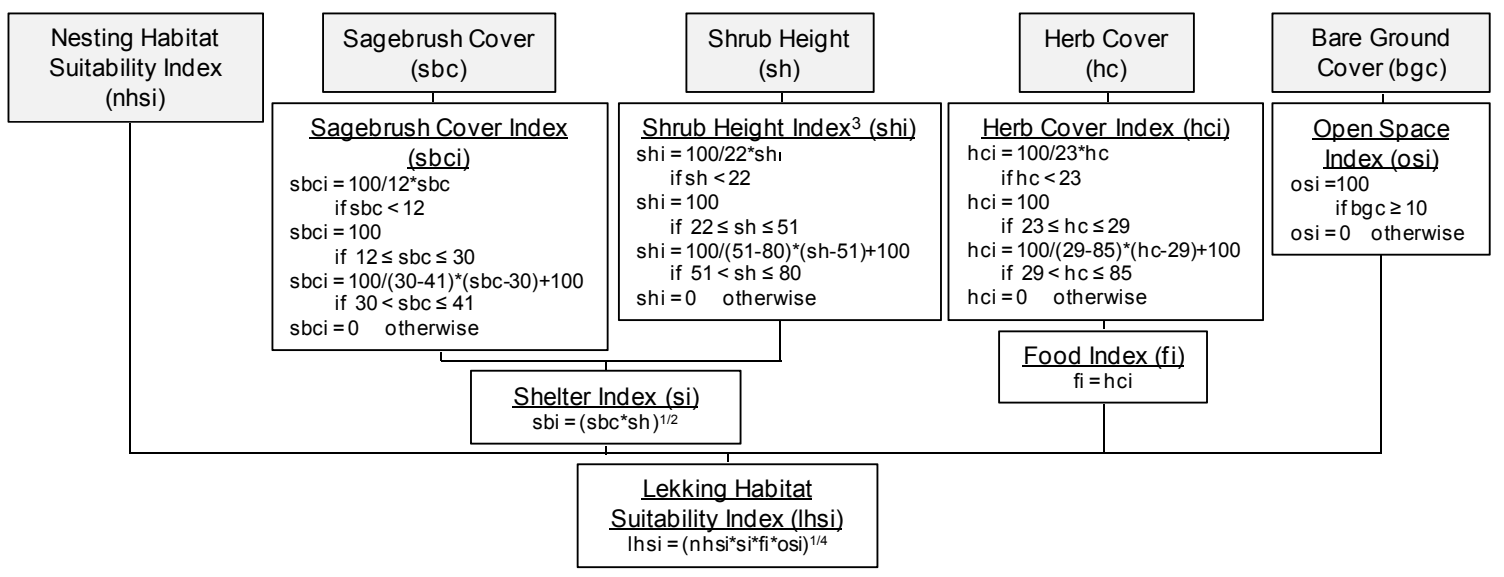

FIGURE 4 Model Used to Determine Sage-Grouse Lekking Habitat Suitability 
There is little published information on food and shelter components of habitats used offlek during the lekking period. Therefore, we applied the thresholds and functions for the food index and the sagebrush index (for shelter) from the nesting habitat suitability model. We used the four indices representing open space, nest proximity, shelter, and food to calculate the lekking HSI value of each pixel (Figure 4), and applied a $1-\mathrm{km}^{2}$ average filter (representing a typical lekking habitat range) to produce the lekking HSI map. In order to examine the reliability of the lekking HSI map, we qualitatively compared our lekking HSI map to the map of observed lek locations that had been converted to a geospatial layer (Table 1). We also extracted HSI values from the 64 lek locations observed in the study area and 64 randomly selected points outside the core area. We computed summary statistics of these two samples and performed a t-test to determine significance in HSI values between the observed leks and non-lek locations.

\subsubsection{Early Brood-Rearing Habitat Suitability Model}

We developed a habitat suitability model of early brood-rearing habitats using three components: food, shelter, and nest proximity (nesting HSI). We characterized food availability based on the overall cover fraction of herbaceous plants (i.e., combination of grasses and forbs) using the herb fractional cover map (Table 1). We considered a range of optimal herb cover to be between 16.2\% and 45.8\% (Connelly et al. 2004; Crawford et al. 2004; Figure 5). For herb cover fractions below $16.2 \%$ or above $45.8 \%$, the index value increased from 0 to 100 or decreased from 100 to 0 linearly with cover fraction, respectively.

We determined the shelter component for early brood-rearing habitats using three factors: sagebrush cover, shrub height, and grass height. We first computed indices of sagebrush cover and shrub height to characterize shrubs within the habitat using the sagebrush cover fraction and shrub height maps (Table 1). We considered the range of optimal sagebrush cover to be between $8.8 \%$ and $38 \%$ (Figure 5 ). For sagebrush cover below $8.8 \%$ or above $38 \%$, the index value increased from 0 to 100 or decreased from 100 to 0 linearly with cover fraction, respectively.

We considered the range of optimal shrub height to be between $16.5 \mathrm{~cm}$ and $83 \mathrm{~cm}$, based on Connelly et al. (2004). For shrub height below $16.5 \mathrm{~cm}$ or above $83 \mathrm{~cm}$, the index value increased from 0 to 100 or decreased from 100 to 0 linearly with height, respectively. We used the sagebrush cover index and shrub height index to compute the sagebrush index.

Similar to our approach for nesting habitat suitability, we used data on the occurrence of grasses and forbs from the NWGAP land cover map as a surrogate measure to determine the value for our grass index. Using the NWGAP land cover map (Table 1), we assigned a value of 100 to habitats containing tall grass species and a value of 50 to all others. We then used the tallgrass index and the herb cover index to calculate the grass index (Figure 5). We computed the shelter index by integrating the grass index and the sagebrush index. Finally, we used the food, shelter, and nesting habitat suitability indices to calculate the early brood-rearing HSI value for each pixel, and applied a $2.5-\mathrm{km}^{2}$ average filter (representing a typical early brood-rearing habitat range) to produce the early brood-rearing HSI map. 


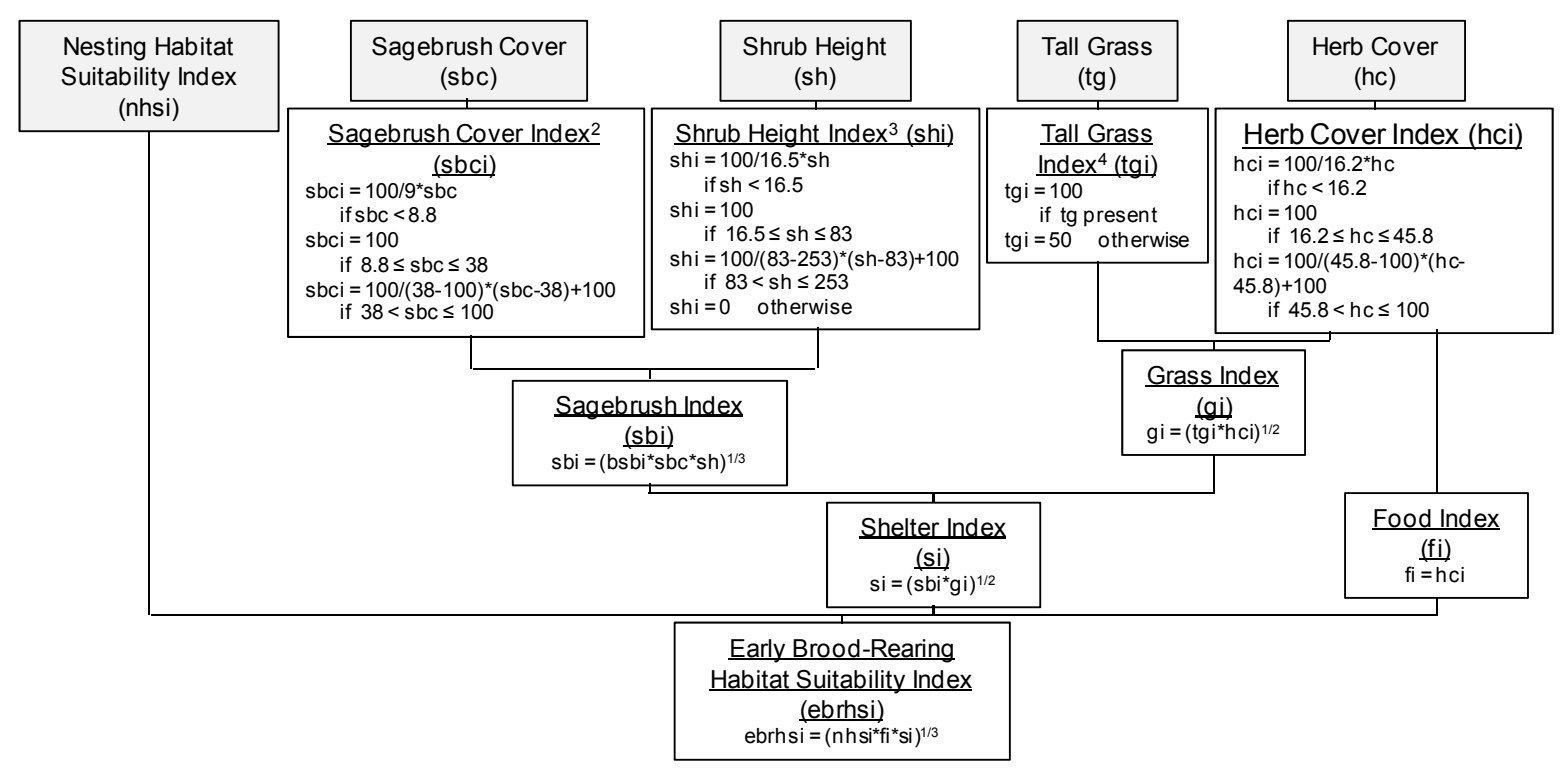

FIGURE 5 Model Used to Determine Sage-Grouse Early Brood-Rearing Habitat Suitability

We performed both qualitative and quantitative assessments to examine the level of agreement between our early brood-rearing HSI map and the map of greater sage-grouse core areas (WGFD 2010). We sampled early brood-rearing HSI values at 150 randomly selected pixels from within core areas and outside core areas. We computed summary statistics of these two samples and performed a t-test to determine the significance of HSI values between sample values inside and outside of core areas.

\subsubsection{Summer Habitat Suitability Model}

We developed a habitat suitability model of summer habitats using two components: food and shelter. We estimated the availability of food based on the herb cover within the habitat (Figure 6). We considered the optimal herb cover to be $32 \%$ or greater, based on Holloran (1999). The herb cover index value increased linearly from 0 to 100 with herb cover fraction until the cover reached $32 \%$. For mesic habitats, we considered this herb cover index as equivalent to the food index. For non-mesic habitats, such as sagebrush habitats where food sources are limited during the dry season, we computed the availability of mesic habitats within a 450-m radius (i.e., food accessibility index). We then weighted the herb cover index by this food accessibility index in order to obtain the food index for non-mesic habitats.

For characterizing the shelter component of summer habitats, we first computed a sagebrush cover index and shrub height index. We considered a range of optimal sagebrush cover to be between $10 \%$ and $25 \%$, based on information in Wambolt et al. (2002) (Figure 6). For sagebrush cover fractions below $10 \%$ or above $25 \%$, the index value increased from 0 to 100 or decreased from 100 to 0 linearly with cover fraction, respectively. We considered the optimal shrub height to be $17 \mathrm{~cm}$ or greater (Wallestad 1971). For shrub heights below $17 \mathrm{~cm}$, the index 


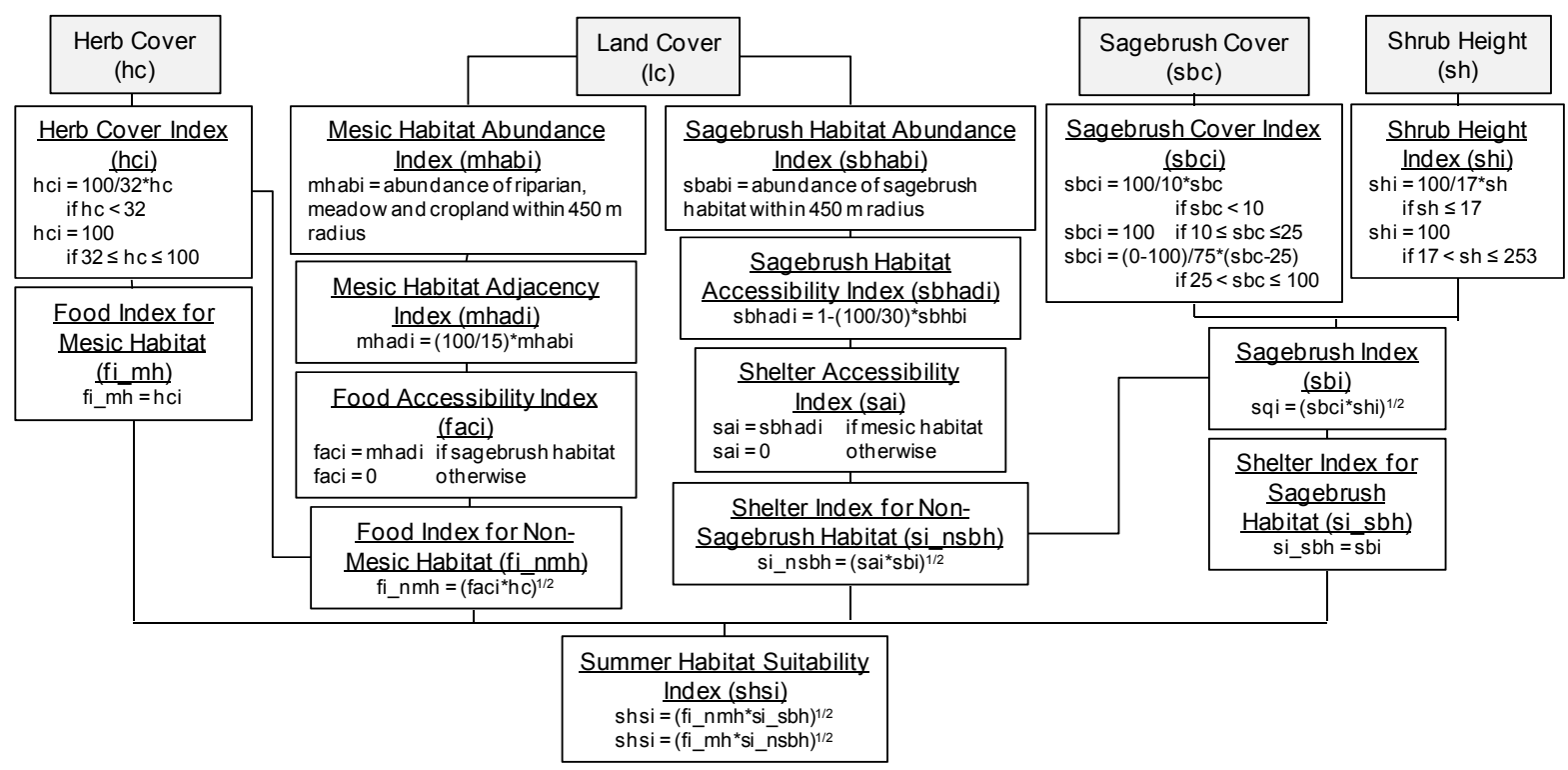

FIGURE 6 Model Used to Determine Sage-Grouse Summer Habitat Suitability

value increased from 0 to 100 linearly with height. We used the sagebrush cover index and shrub height index to compute the sagebrush index (Figure 6). For sagebrush habitats, this sagebrush index value was used as the shelter index value. For non-sagebrush habitats where high-quality shelter is limited, we determined the availability of sagebrush habitats within a $450-\mathrm{m}$ radius (i.e., shelter accessibility index). We then weighted the sagebrush index by the shelter accessibility index to obtain the shelter index for non-sagebrush habitats. Finally, we used the shelter and food indices to calculate the summer HSI value of each pixel (Figure 6), and applied a $25-\mathrm{km}^{2}$ average filter (representing a average summer habitat range) to produce the summer HSI map. We did not perform a quantitative assessment of our summer habitat suitability maps because summer habitat is not expected to correspond well to the identified core areas, and an alternative published habitat suitability map was not available.

\subsubsection{Winter Habitat Suitability Model}

We developed a habitat suitability model of winter habitats using three components: food, shelter, and topography; food and shelter were combined into a single index (Figure 7). We determined food availability using sagebrush cover and shrub height within habitats. We considered the range of optimal sagebrush cover to be between $10 \%$ and $30 \%$. For sagebrush cover below $10 \%$ or above $30 \%$, the index value increased from 0 to 100 or decreased from 100 to 0 linearly with cover, respectively. We considered the range of optimal shrub height to be between $20 \mathrm{~cm}$ and $80 \mathrm{~cm}$ (Crawford et al. 2004). For shrub heights below $20 \mathrm{~cm}$ or above $80 \mathrm{~cm}$, the index value increased from 0 to 100 or decreased from 100 to 0 linearly with height, respectively. We used the sagebrush cover index and shrub height index to compute the foodshelter index (Figure 7). We considered the optimal slope for winter habitats to be $10 \%$ or less, 


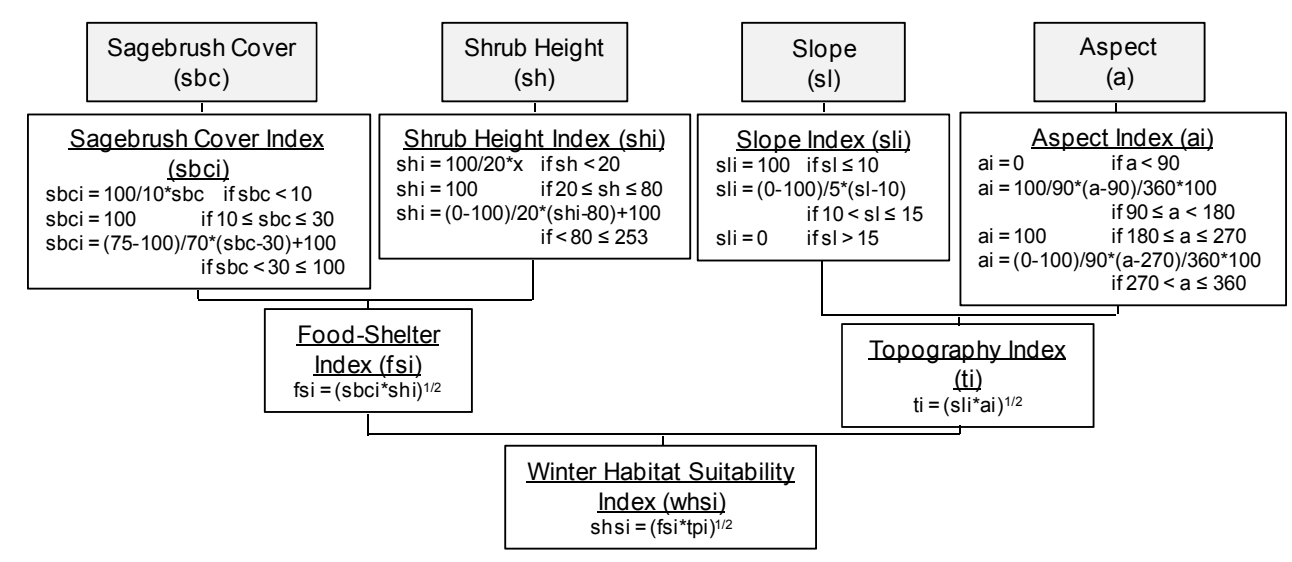

FIGURE 7 Model Used to Determine Sage-Grouse Winter Habitat Suitability

based on information in Connelly et al. (2004) and Doherty et al. (2006) (Figure 7). The maximum usable slope was considered to be $15 \%$. For slopes between $10 \%$ and $15 \%$, the index value decreased from 100 to 0 linearly with slope. We considered the optimal aspect to be between a south- and west-facing slope (i.e., 180-270 degrees) (Beck 1977; Crawford et al. 2004; Eng and Schladweiler 1972; Hupp and Braun 1989). For aspects between 90 degrees and 180 degrees or 270 degrees and 360 degrees, the index value increased from 0 to 100 or decreased from 100 to 0 linearly with aspect, respectively. We considered aspects less than 90 degrees to be unsuitable (aspect index $=0$ ). We calculated the topography index by combining the slope index and aspect index as shown in Figure 7. Finally, we used the food-shelter and topography indices to calculate the winter HSI value for each pixel, and applied a $25-\mathrm{km}^{2}$ average filter (representing a typical winter habitat range) to produce the winter HSI map. We determined the reasonableness of our winter HSI map by applying the resource selection function originally developed for the Powder River Basin by Doherty et al. (2008) to our study area and qualitatively compared the resulting map to our winter HSI map.

\subsection{HABITAT SUITABILITY MODEL RESULTS}

The seasonal HSI maps we developed using the data and approaches described in Sections 4.1 and 4.2 are shown in Figure 8. Habitats with relatively high suitability values (i.e., HSI > 70) were unevenly distributed in the study area. Most suitable sage-grouse habitat in the study area occurs in an approximately northwest- to southeast-trending swath of shrub-steppe habitat. Areas to the northeast and southwest of this swath have more rugged topography that provides less-suitable habitat.

Areas modeled as having high suitability during the lekking, nesting, and early broodrearing seasons are mostly concentrated in the northern half of the study area. The locations of highly suitable areas for these three habitats are collocated because nesting habitat suitability is one of the key factors for determining the suitability of lekking and early brood-rearing habitats. 

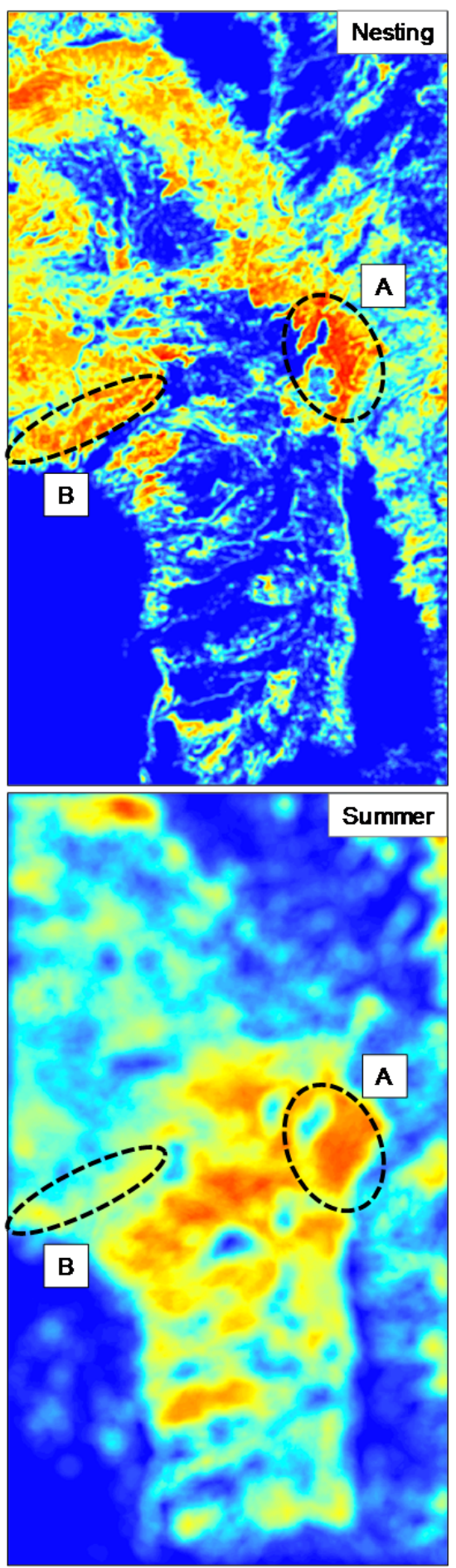
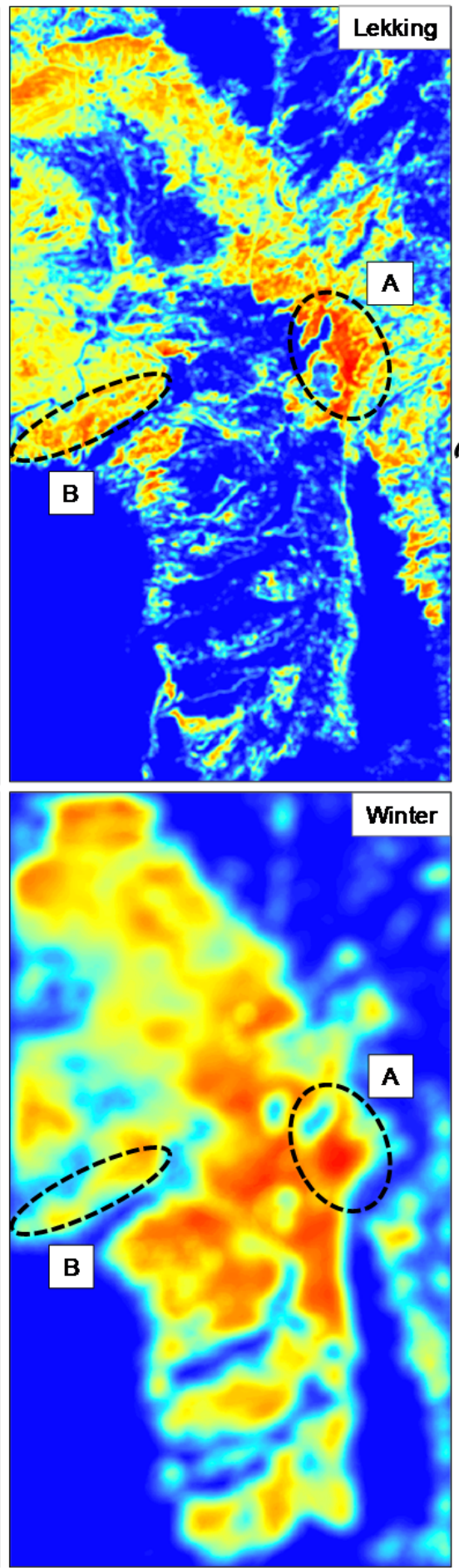

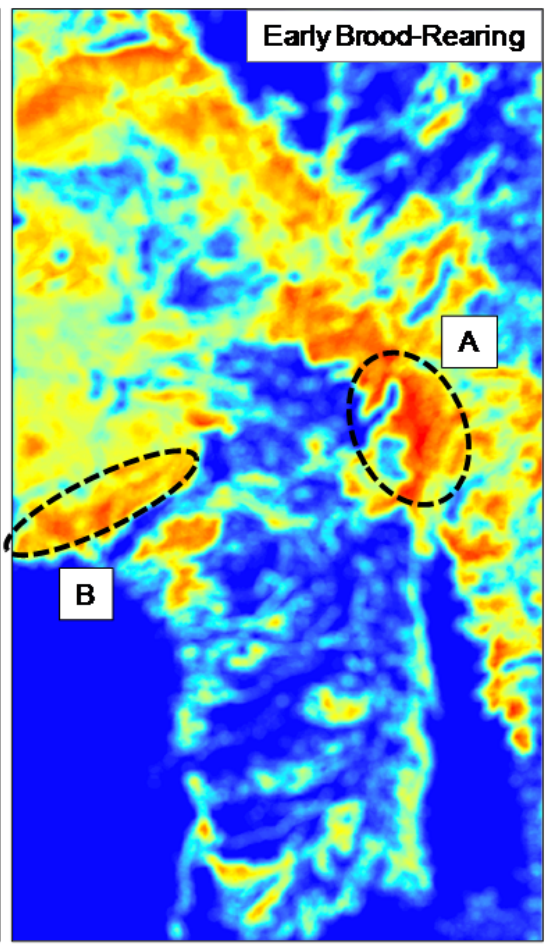

Habilat Sutabifity Index

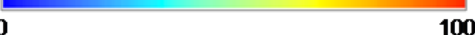

FIGURE 8 Modeled Seasonal Sage-Grouse HSI Maps (Habitat suitability ranged from 0 [no suitability] to 100 [optimal suitability]. Area $A$ is an example of suitable habitat year-round while Area $B$ is an example of an area that does not have suitable habitat in all seasons.) 
Areas modeled as having high-suitability summer habitat are located mostly near the center of the study area (Figure 8). Summer habitats in the study area support relatively abundant forb growth and are limited to riparian habitat, croplands, and meadows, which are outside traditional sagebrush habitats.

Areas modeled as having high-suitability winter habitats are located in the center and northwestern portions of the study area. The distribution of suitable winter habitats, which predominantly depends on the availability of sagebrush species, shares some similarity with the distribution of suitable spring habitats. Suitable winter habitats are distributed more continuously and over a broader portion of the study area than other habitat types.

As shown in Figure 8, highly suitable seasonal habitats are distributed discontinuously across the study area. Because the population of the sage-grouse in the study area is considered non-migratory, suitable habitats for all life-history stages must be located within typical travel distances to support a viable population. In Figure 8, two locations with high-suitability habitat are labeled "A" and "B." Area A provides high suitability habitat in all seasons, but Area B exhibits high suitability during all seasons but summer. In addition, Area B has very limited high-quality summer habitat within close proximity. Therefore, Area B may not be able to support a viable population because all seasonal habitat needs cannot be met.

As mentioned in Section 4.2, the reasonableness of our habitat suitability models was examined by comparing our HSI maps to available information on core areas (WGFD 2010), lek locations (Novotny 2010), and a published winter habitat suitability model (Doherty et al. 2008). In general, we found good agreement between our seasonal habitat maps and these other sources of information (Figure 9). The core areas indicate important sage-grouse habitats in the northern half of the study area, which correlates well with our nesting and early brood-rearing maps. Most of the known lek locations occur in areas we mapped as highly suitable lekking habitat. Sagegrouse core areas also match fairly well with areas we mapped as highly suitable. Overall spatial distributions of highly suitable winter habitats resemble those in the winter HSI map we generated using the winter habitat suitability model of Doherty et al. (2008).

The results of our quantitative assessment of agreement between the three spring HSI maps (nesting, early brood-rearing, and lekking habitat maps) are shown in Table 2. Although mean HSI values at observed lek locations and within sage-grouse core areas were not as high as we expected, statistics suggests that the values are significantly higher than those outside the core areas and observed lek locations. The relatively low modeled HSI values that were sampled from inside the core areas may be explained by the following: (1) some environmental variables describing habitat suitability in our current model have greater importance than other variables, (2) there are other important variables that are not currently included in our models, or (3) the core areas do not accurately reflect habitat suitability. 

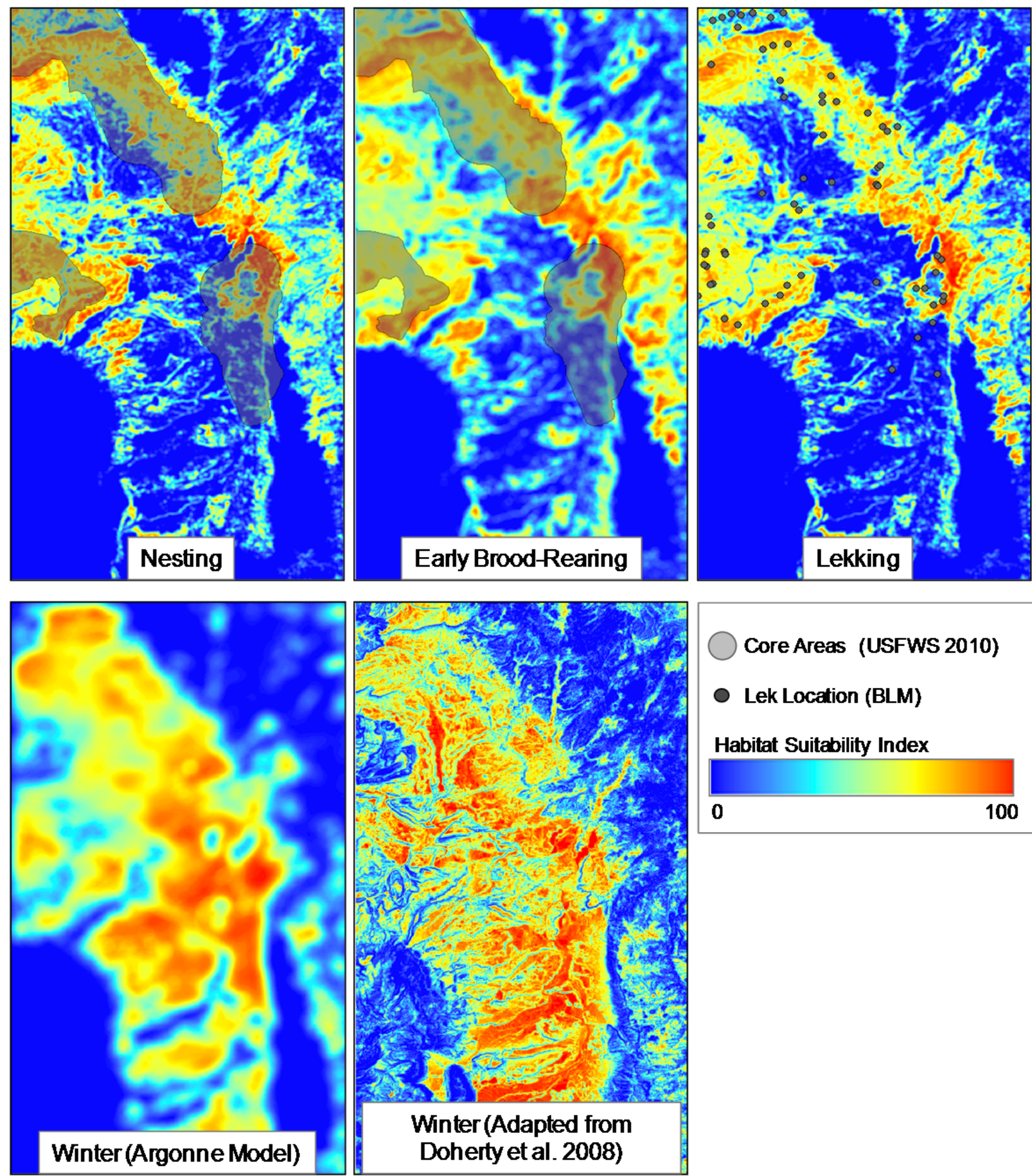

Core Areas (USFWS 2010)

- Lek Location (BLM)

Habitat Suitability Index

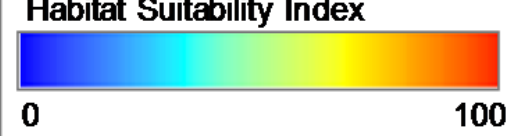

FIGURE 9 Modeled Seasonal Sage-Grouse HSI Maps Compared to Published Information

(Nesting and brood-rearing habitat maps are overlain with breeding density areas; the lekking map shows the location of known leks; and the winter map is compared to a winter HSI map generated using a published model.) 
TABLE 2 Comparisons of Computed HSI Values Inside and Outside of Sage-Grouse Core Areas $^{a}$ and Documented Lek Locations ${ }^{b}$

\begin{tabular}{|c|c|c|c|c|c|c|}
\hline \multirow[b]{3}{*}{ Parameter } & \multicolumn{2}{|c|}{ Nesting HSI } & \multicolumn{2}{|c|}{ Early Brood-Rearing HSI } & \multirow{2}{*}{\multicolumn{2}{|c|}{ Lekking HSI }} \\
\hline & \multirow[b]{2}{*}{$\begin{array}{c}\text { Within } \\
\text { Core Areas }\end{array}$} & \multirow[b]{2}{*}{$\begin{array}{c}\text { Outside } \\
\text { Core Areas }\end{array}$} & \multirow[b]{2}{*}{$\begin{array}{c}\text { Within } \\
\text { Core Areas }\end{array}$} & \multirow[b]{2}{*}{$\begin{array}{c}\text { Outside } \\
\text { Core Areas }\end{array}$} & & \\
\hline & & & & & Lekking & No-Lekking \\
\hline Mean HSI Value & 47.3 & 17.2 & 52.0 & 21.6 & 45.5 & 15.1 \\
\hline Standard Deviation & 28.5 & 24.0 & 26.2 & 25.6 & 25.1 & 22.4 \\
\hline$P>t$ & \multicolumn{2}{|c|}{$<0.001$} & \multicolumn{2}{|c|}{$<0.001$} & \multicolumn{2}{|c|}{$<0.001$} \\
\hline
\end{tabular}

a Sample locations inside and outside greater sage-grouse core areas as mapped by WGFD (2010).

b Lek locations documented in Novotny (2010).

\subsection{MODELING THE IMPACT OF WIND DEVELOPMENT AND ASSOCIATED INFRASTRUCTURE}

We modeled two potential effects of wind energy infrastructure on sage-grouse: reductions in the survivorship of individuals and reductions in habitat suitability. We gathered information on the potential impact of energy infrastructure on sage-grouse survivorship from multiple sources (Becker et al. 2009; Holloran 2005; Kaiser 2006). Information about the impact of various infrastructures on sage-grouse is very limited in the existing literature. However, quantitative information on the impact of roads and wells are relatively well documented.

Geospatial data for these three infrastructure types included the number of units, power capacity, ownership, and status. We obtained a road vector layer from the Highway Performance Monitoring System (available at http://www.fhwa.dot.gov/policyinformation/hpms.cfm). The data reflect the extent, condition, performance, use, and operating characteristics of highways. We converted geospatial data to a 30-m resolution binary raster layer representing occurrence of infrastructure. We counted the number of cells containing infrastructure within $6 \mathrm{~km}$ of each pixel in $240 \mathrm{~m}$ radial increments. Therefore, each pixel was assigned 25 values that represented the occurrence of infrastructure at increasing distances. We then spatially subsetted (i.e., clipped) the occurrence and abundance layers to match the spatial extent of other geospatial layers used in this project.

For our proof of concept, the impact of all infrastructure types on sage-grouse is represented as equal. Because of information availability, we chose to apply the data for oil and gas wells and roads as surrogate measures for the impact of all infrastructure in our model. We assume using these data as surrogates for wind energy development effects presents a worst-case scenario, and the actual effect of wind infrastructure would be less. All mortality-related calculations are based on survival probabilities (input parameters) in order to simplify computations and reduce the possibility of error. The probability of surviving exposure to 
multiple mortality sources is calculated simply by multiplying the individual survival probabilities together.

Infrastructure can affect sage-grouse survivorship through predation and collision. Infrastructure potentially increases predation rates by providing perches for sage-grouse predators (e.g., hawks and ravens [Corvus corax]) or increasing access to habitats by mammalian predators. Infrastructure also can affect survivorship by increasing collision mortality resulting from strikes with linear structures such as turbines, poles, and transmission lines and towers, and vehicles.

We modeled these infrastructure effects as a distance-related proportional decrease in survivorship (i.e., survivorship increases with distance from infrastructure). A linear function was developed based on published data indicating the quantitative relationship between proximity to infrastructure and survivorship derived from observed effects of infrastructure on survivorship for three age classes at different distances (Becker et al. 2009; Holloran 2005; Kaiser 2006) (Figure 10). We assumed a linear relationship between survivorship and distance for simplicity, and the slope value was determined from the points that make up the relationship. This assumption of linearity does have potential consequences for estimates at intermediate distances, but they are expected to be relatively insignificant. Given a lack of observed data on how wind energy developments affect sage-grouse, the model uses information on the impacts of other infrastructure as a proxy. Survivorship of individual grouse was weighted by applying the corresponding function to the baseline survivorship values in the IBM.

We also modeled the effects of infrastructure on habitat suitability to account for loss and degradation of sage-grouse habitats due to infrastructure development. We used the geospatial layers of infrastructure occurrence and abundance in the model. Specific details about modeled impacts of wind development on habitat suitability are discussed in Section 5.
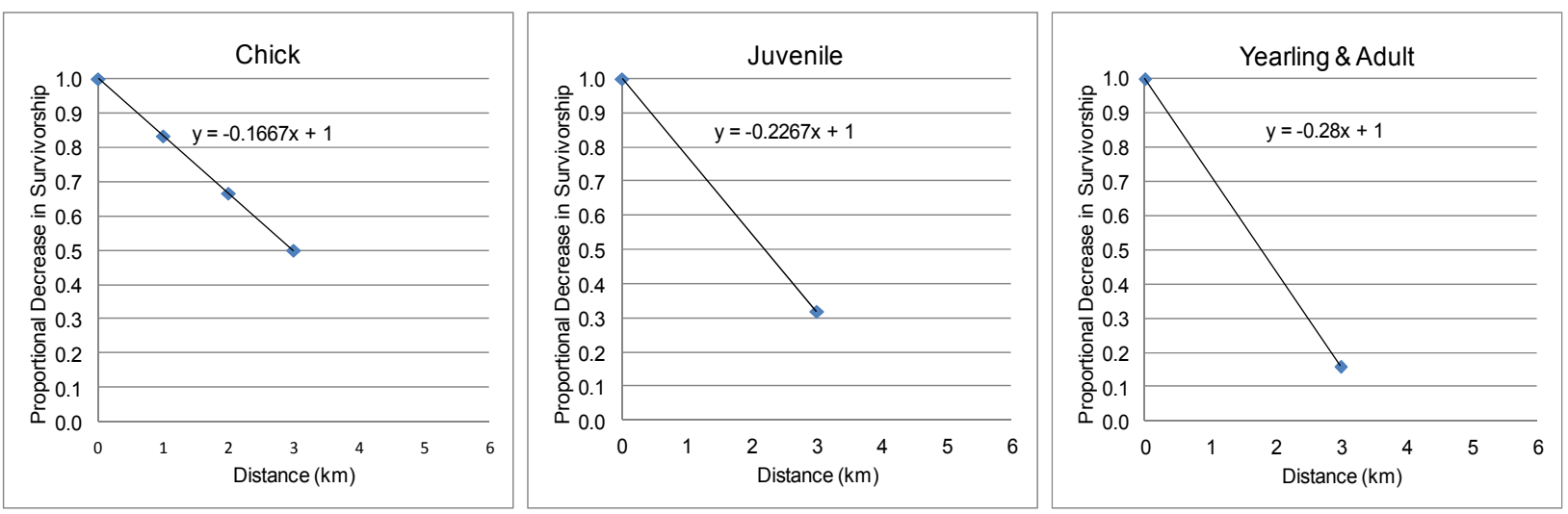

FIGURE 10 Proportional Decrease in Sage-Grouse Survivorship in Relation to Distance from Infrastructure 
The resulting maps of the effects of infrastructure on survivorship of the three sagegrouse age classes are shown in Figure 11. As shown in Figure 10, the effect of infrastructure on survivorship was assumed to be greater for younger birds. For yearlings and adults, the infrastructure effects become relatively minor (about $10 \%$ decrease in survivorship) at a distance greater than $3.5 \mathrm{~km}$. For areas within approximately $335 \mathrm{~m}$ of infrastructure, survivorship was reduced by about $90 \%$ for all age groups.

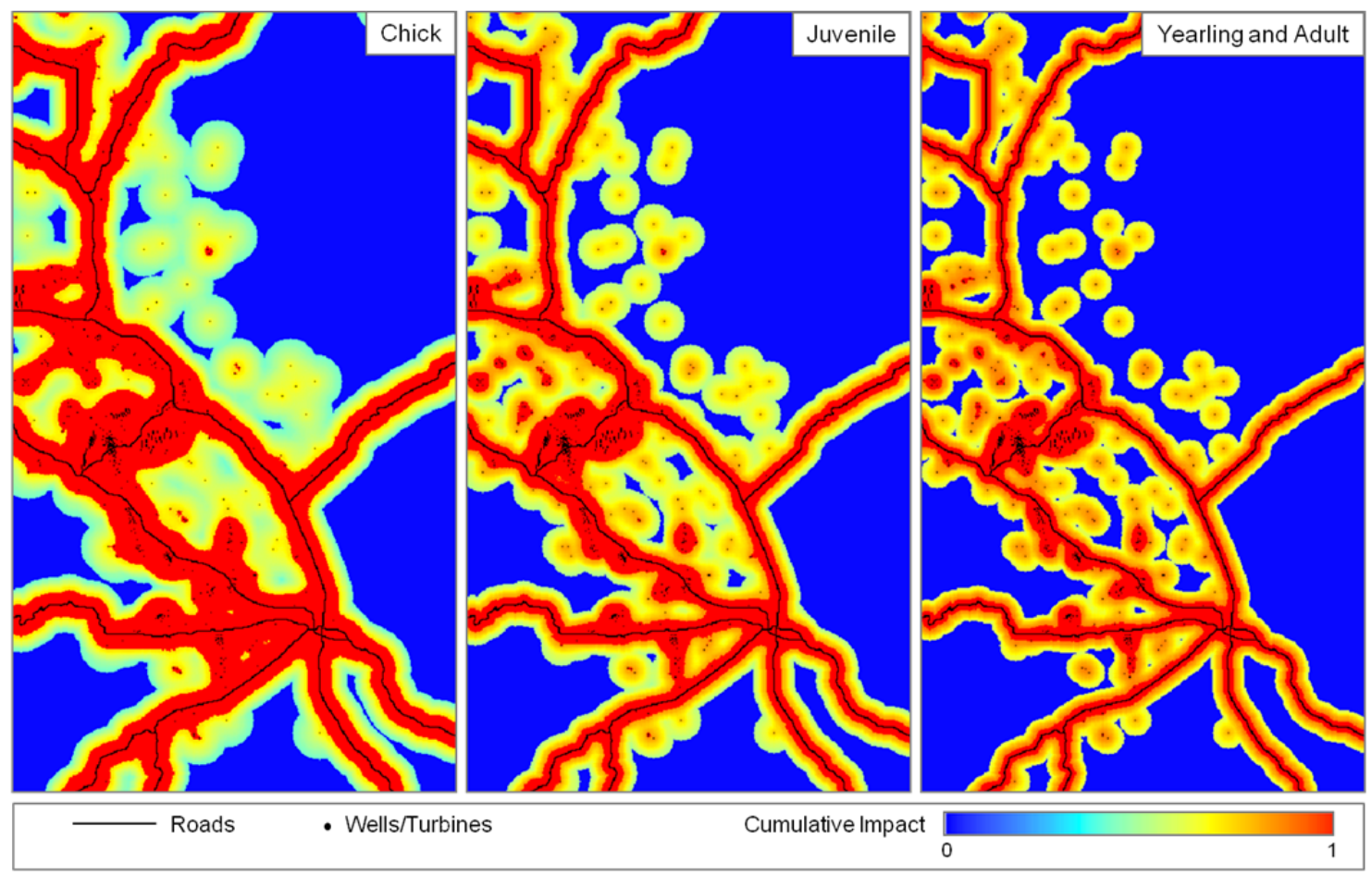

FIGURE 11 Mapped Infrastructure Effects on Survivorship of Sage-Grouse Age Classes (Cumulative impact ranged from 0 [no effect on survivorship] to 1 [survivorship reduced to 0$]$.)

\section{MODELING INDIVIDUAL SAGE-GROUSE}

We utilized an individual-based modeling approach to project the effects of landscapelevel characteristics and developments on the greater sage-grouse of our study area. IBMs are based on the premise that population-level phenomena are ultimately emergent properties of the interactions between individuals and their environment. By modeling these interactions using well-understood relationships, the modeler can better predict and understand population-level changes. This section describes our overall individual-based modeling approach. 


\subsection{OVERVIEW OF SAGE-GROUSE IBM}

Our sage-grouse IBM was developed on the NetLogo modeling platform: a multi-agent programmable modeling environment authored at the Northwestern University Center for Connected Learning and Computer Based Modeling (available at http://ccl.northwestern.edu). NetLogo utilizes an object-oriented programming language, so the IBM was designed according to an object-oriented methodology. Explicitly designed for IBMs of mobile individuals with local interactions in a grid space, it is considered to be one of the highest-level modeling platforms due to its simple yet powerful programming language, built-in graphical interfaces, and comprehensive documentation. As a result, it is highly recommended for prototyping complex models (Railsback and Grimm 2011). Details of our approach are presented in Section 5.2.

Our IBM is based on the sage-grouse life history conceptual model shown in Figure 2, and our habitat suitability models described in Section 4. The IBM estimates the spatial and temporal movements of sage-grouse based on modeled effects of habitat characteristics and developments on sage-grouse condition, survivorship, and reproduction. In the model, we represented the study area as a collection of discrete, uniform, square cells (habitat conditions differ among cells, but not within a cell). Four distinct age classes of sage-grouse are represented in the model (Section 3): adults, yearlings, juveniles, and chicks (chicks and juvenile sage-grouse are assumed to be completely dependent upon their mother, and move with her between seasons).

In our model, each individual occupies one cell each season that represents the center of its seasonal home range. Home ranges vary in size according to season (Section 4). All cells (with the exception of a lek) can be occupied by only one yearling or adult individual during a season. The HSI value of a cell represents the average for all cells within the home range and that HSI value is used in the daily calculation of that individual's condition during its occupancy. The competition for habitat resources and the impact of infrastructure development are both represented by a reduction of the HSI values of occupied/developed cells within an individual's home range. This method is used to represent the various habitat characteristics that an individual would be exposed to as it made daily movements across its home range.

We model habitat selection as a predictive indirect fitness-maximizing behavior based on the observation that sage-grouse exhibit memory-based seasonal site fidelity. In selecting a seasonal home range, the model assumes individuals preferentially select the first unoccupied cell nearest to the cell occupied during the same season in the previous year. If there is more than one unoccupied cell in the nearest distance, then the individual selects the cell that has the highest seasonal HSI value. It is assumed that sage-grouse are aware of the impact of infrastructure on habitat suitability, but are unable to consider the presence of future competitors during habitat selection. The model uses a condition-based dominance hierarchy that determines the order in which individuals select seasonal habitat. The sage-grouse with the highest condition value selects its cell first and the cell is no longer considered a potential habitat for other individuals. Individuals base their habitat selection in turn on the remaining cells unoccupied by higher-ranking (better condition) sage-grouse. 
Our model assumes that every adult/yearling female sage-grouse attending a lek will mate and subsequently initiate a nest. Production of offspring is modeled stochastically based on the probability of reproduction, which along with the number of offspring produced is a function of the female's condition. If females successfully produce young, they next select and move to early brood-rearing habitat; unsuccessful females select and move directly to summer habitat. Reproductive success of males is not considered in the model.

We model the survival of individual sage-grouse as a stochastic process. Observed annual survivorship probabilities for each age-sex class were transformed by a constant function assuming a corresponding average HSI value. For each individual, the model calculates a scaled daily probability of survival as a function of condition and the assumed impact of infrastructure development on survivorship. Although, in our model, sage-grouse are aware of the impact of infrastructure on habitat suitability as stated earlier, it is assumed that they are unaware of the impact on survivorship during habitat selection. The actual survival of an individual is modeled stochastically based on the scaled survival probability.

The abridged schedule shown in Table 3 provides a summary of actions in the order executed within the IBM based on the life history of sage-grouse.

TABLE 3 Modeled Sage-Grouse Actions

Feature

Habitat Selection

Reproduction

Movement

Condition

Survivorship
Action

Select destination cell in order of dominance hierarchy prior to seasonal transition Determine reproduction prior to the end of nesting season Move between source cell and destination cell during seasonal transition Evaluate condition each day of cell occupancy Assess survivorship each day of cell occupancy

\subsection{DESCRIPTION OF THE SAGE-GROUSE IBM}

This section presents details of our sage-grouse IBM. Included in this section are definitions of the terms used, modeling conventions, model objects, and the functions and relationships that form the basis of model calculations. The IBM overview presented in Section 5.1 provides sufficient detail for a basic understanding of the IBM.

\subsubsection{Terminology}

We use the following terms to describe elements and characteristics of our sage-grouse IBM. These terms and their definitions are consistent with guidelines presented by Grimm and Railsback (2005). 
Action: The basic element of the model that is executed during a model run. Actions are associated with objects, methods, and schedule.

Behavior: The operations of an individual sage-grouse within the model.

Cell: The basic unit of habitat in the model (equivalent to a pixel). A cell occupied by an individual sage-grouse in a season is located at the center of the individual's home range. The habitat suitability and other values associated with that cell represent an average of all pixel values within the individual's home range.

Condition: A measurement of relative body condition that influences position in the dominance hierarchy, habitat selection, survivorship, and reproductive success.

Fitness: A measurement of an individual's ability to survive and reproduce, assumed to be directly related to body condition.

Habitat Selection: The behavior and corresponding movement that determines which cell (home range center) a sage-grouse will occupy in the following season.

Method: An algorithm that executes one particular trait, behavior, or process.

Object: A discrete entity within the model with its own state variables (e.g., individual sagegrouse and cells).

Population: The collection of individual sage-grouse within a simulation.

Sage-grouse: Virtual representations of individual birds within the model.

Scenario: A set of inputs to the model representing specific infrastructure locations and habitat conditions.

Schedule: The order in which modeled events occur. The schedule defines the actions and the rules of their execution.

Season: Each portion of the year specifically marked by occupancy of habitats according to the life history of sage-grouse. Movement between seasonal habitats occurs at the transition between seasons.

State: A measure of the status of an aspect of the model that typically can be described using a single number (e.g., age of sage-grouse and HSI value of cells).

Trait: A set of rules for individual operations at particular times and/or in response to specific circumstances in the model. 


\subsubsection{Conventions}

We used the following conventions when developing the IBM.

Spatial Scales: Space was represented as a collection of discrete, uniform, square cells; habitat conditions differed among cells but not within a cell. The spatial resolution of the model $(240 \mathrm{~m})$ was the size of one cell. All object locations were referenced to the center of their respective cells; the distance between two cells was calculated as the straight-line distance between the centers of the cells.

Temporal Scales: Time was modeled using discrete daily time steps. A day of the year calendar (not including leap years), numbered 1 to 365 , was used. Seasonal actions for male and female sage-grouse are presented in Table 4.

Variable Names: We employed a variable naming convention, common to the NetLogo software platform, that we used to design the IBM. Variable names were formed by joining several descriptive words, making them easy to identify. The first word starts with a lower-case letter, and subsequent words are capitalized (e.g., habitatSuitabilityBaseline). For documentation purposes, composite variables consisting of multiple factors were employed when applicable in order to simplify the representation of calculations.

\subsubsection{Modeled Objects and Related Functions}

We used the following detailed assumptions and corresponding equations to define the behaviors or traits of objects in the IBM.

TABLE 4 Modeled Seasonal Habitats and Movements of Male and Female Sage-Grouse in Different Seasons

\begin{tabular}{lll}
\hline \multicolumn{1}{c}{ Time of Year } & \multicolumn{1}{c}{ Male Habitats } & \multicolumn{1}{c}{ Female Habitats } \\
\hline \multirow{2}{*}{ Winter } & Winter & Winter \\
Spring & Lek & Nest $\rightarrow$ Lek $\rightarrow$ Nest $\rightarrow$ Early Brood-Rearing \\
Summer & Summer & Summer \\
Autumn & Summer $\rightarrow$ Winter & Summer $\rightarrow$ Winter \\
\hline
\end{tabular}

\subsubsection{Cells}

Habitat was depicted in the model at the cell level (240-m pixel). Habitat suitability values for each cell were based on the HSI values modeled, mapped, and described in Section 4. The HSI value of each cell represented the average HSI value of all pixels that fell within a 
seasonal home range size based on published size values. There were two cell types that were treated differently than this (infrastructure cells and lek cells), as described next.

\section{Infrastructure Cells}

Infrastructure cells represent areas that contain existing development or, for scenario evaluation, proposed development. The effective habitat suitability value of an infrastructure cell is assumed to be zero. Habitat suitability values of cells that represent home ranges containing infrastructure are calculated as a weighted average:

$$
\begin{aligned}
& \text { habitatSuitabilityInfrastructureImpact } \\
& =\frac{[\text { habitatSuitabilityBaseline } \times(\text { homeRangeCount }- \text { homeRangeInfrastructureCount })]}{\text { homeRangeCount }}
\end{aligned}
$$

where the baseline habitat suitability value of the home range is based on the spatial average filter that was employed in the formulation of the HSI maps (Section 4).

The impact of infrastructure on the survivorship of each age-sex class of sage-grouse (Section 4) is a determining factor in their daily probability of survival; a mitigation factor (provisionally set to 0 ) that allows us to examine effectiveness of ecological mitigation is applied as a percentage reduction to the daily impact of infrastructure on survivorship:

$$
\begin{aligned}
& \text { infrastructureImpactMitigate } \\
& \qquad=\sqrt[365]{\{\text { survivorshipInfrastructureImpact } \times[1+(\text { mitigateFactor } / 100)]\}}
\end{aligned}
$$

\section{Lek Cells}

Lek cells represent the traditional mating grounds of sage-grouse. Unlike all other cell objects, leks represent communal areas that are occupied by multiple individuals throughout the lekking season, but are not occupied at other times of the year. The carrying capacity of a lek is calculated based on the assumption that the size of a lek is proportional to its habitat suitability value. The maximum number of attending females and males was considered to be 100 and 60 , respectively, based on (1) our estimation of the maximum number of nesting home ranges that could be established within traveling distance of a lek and (2) the ratio of adult females to males. Lek carrying capacity was then calculated based on the following equations:

lekCarryingCapacity $=$ round $[(100 \times$ lekSuitability $) / 100]$ for females, and

lekCarryingCapacity $=$ round $[(60 \times$ lekSuitability $) / 100]$ for males. 


\subsubsection{Sage-Grouse}

The model depicts four distinct age classes of sage-grouse: adults ( $\geq 104$ weeks), yearlings (41-103 weeks), juveniles (10-40 weeks), and chicks (0-10 weeks). Sage-grouse carry out five distinct actions: habitat selection, reproduction, movement between seasonal habitats, condition evaluation, and mortality assessment (Table 3). Within the larger framework of the sage-grouse life history, the daily behaviors of each individual are age-sex class specific (no sex distinction is made for the chick age class). The five sage-grouse actions and how we modeled them in the IBM are described next.

\section{Habitat Selection}

The following principles provide the basis for the model's representation of habitat selection:

- A condition-based dominance hierarchy determines the order in which individuals select their future habitat;

- Sage-grouse exhibit inter-annual site fidelity to seasonal habitat ranges, and preferentially select a cell closest in proximity to the cell formerly occupied during the corresponding season of the previous year;

- Habitats are selected to maximize condition during a given season within exhibited site fidelity behavior; and

- Sage-grouse are able to make decisions based upon a prediction of their future condition under particular circumstances.

Habitat selection assumes a condition-based dominance hierarchy of adult and yearling sage-grouse; chicks and juvenile sage-grouse are assumed to be completely dependent upon their mother and therefore imitate their mother's habitat selection behavior. The hierarchy is implemented through execution of the habitat selection method in order of descending relative value of condition after a comparison factor parameter (provisionally set to 0.8 ) has been applied to yearlings based on the assumption that biologically mature and experienced individuals will be dominant up to a point over biologically immature and inexperienced individuals. The sagegrouse with the highest value of condition selects its cell first, and that cell (with the exception of leks) is no longer considered a potential habitat for other individuals. Subsequent sage-grouse therefore base their habitat selection on the remaining cells unoccupied by higher-ranking individuals.

Habitat selection begins with the identification of potential destination cells. Sage-grouse populations may be migratory (moving greater than $10 \mathrm{~km}$ between seasonal ranges) or non-migratory (moving less than $10 \mathrm{~km}$ between seasonal ranges) (Connelly et al. 2000); observed travel distances (Connelly et al. 2004; Holloran and Anderson 2005; Holloran 1999; 
Schroeder et al. 1999) provided the basis for our assumption that the study area supports a nonmigratory sage-grouse population with maximum travel distances of $5 \mathrm{~km}$ between lek and nest habitat, $5 \mathrm{~km}$ between nest and early brood-rearing habitat, and $10 \mathrm{~km}$ between all other corresponding seasonal habitats.

Site fidelity is represented in the model through the preferential selection of a cell closest in proximity to the cell occupied during the corresponding season of the previous year with secondary regard for the sage-grouse's expected condition as a result of a period of occupancy. The memory of previously occupied cells is updated annually and passed from a female to its offspring. Equating time with distance in relation to the daily rate of movement (time = distance/ rate) as a means of balancing the effect of occupancy duration on expected condition, individuals only consider unoccupied cells with the highest value of habitat suitability as alternative destinations within incremental radial distances from the cell occupied in the previous year (less than or equal to the maximum travel distance from the currently occupied cell) up until the first unoccupied cell(s) with the highest suitability has been identified. Due to the interdependence of lek, nest, and early brood-rearing habitat location, the female selection of habitat for each of these seasons occurs concurrently. Prior to mating season, all sage-grouse preferentially select the lek (that has not reached its carrying capacity of 60 males and 100 females) closest to the lek formerly occupied during the previous mating season. Leks are not considered potential destination cells at any other time of the year.

Sage-grouse evaluate potential destination cells to determine their expected condition as a result of a period of occupancy. The calculation of expected condition in the evaluation of potential destination cells, which is discussed in the Condition subsection, includes the impact of infrastructure on the value of habitat suitability. The value of condition tends toward the value of habitat suitability with a constant rate of change based on the difference between the two values and a limiting factor of occupancy duration. It is assumed that individuals are unaware of the impact of infrastructure on survivorship or of the competition for habitat resources associated with the occupancy of a given potential destination cell when evaluating their potential destinations.

The following steps describe the method used in the model to calculate the value of condition in the evaluation of potential destination cells:

1. The baseline habitat suitability value of the home range is based on the spatial average filter that was employed in the formulation of the HSI maps (Section 4).

2. The impact of infrastructure on the value of habitat suitability is calculated. The effective habitat suitability value of an infrastructure cell is assumed to be zero and the weighted average value of the cells within the home range is determined as described under "Infrastructure Cells."

3. The rate of change of the value of condition is calculated. The absolute value of the difference between the value of habitat suitability (accounting for the 
cumulative impact of infrastructure) and the value of condition divided by the theoretical maximum difference expressed as a number of days of occupancy (provisionally set to 100) is determined:

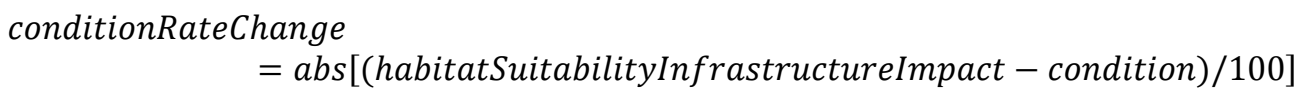

4. The value of condition is calculated when evaluating potential destination cells. A piecewise function was applied as the value of condition tends toward the value of habitat suitability with a limiting factor of occupancy duration. The following sets of equations were used to calculate condition change:

a. If

condition < habitatSuitabilityInfrastructureImpact

then

$\{($ condition $)+[($ occupancyDays -1$) \times$ conditionRateChange $]\}$ $<$ habitatSuitabilityInfrastructureImpact

else

$\{($ condition $)-[($ occupancyDays -1$) \times$ conditionRateChange $]\}>$ habitatSuitabilityInfrastructureImpact

b. If

$\{($ condition $)+[($ occupancyDays -1$) \times$ conditionRateChange $]\}$ $<$ habitatSuitabilityInfrastructureImpact

then

(habitatSuitabilityInfrastructureImpact

$-\{$ condition $+[$ conditionRateChange $\times($ occupancyDays -1$)]\})$

$\geq$ conditionRateChange

else

condition $=$ habitatSuitabilityInfrastructureImpact

c. If

(habitatSuitabilityInfrastructureImpact $-\{$ condition + [conditionRateChange $\times$ (occupancyDays -1$)]\}) \geq$ conditionRateChange

then condition $=$ condition $+($ occupancyDays $\times$ conditionRateChange $)$ 
Development on Sage-Grouse

else

condition

$$
\begin{aligned}
& =\{\text { condition }+[\text { conditionRateChange } \times(\text { occupancyDays }-1)]\} \\
& +(\text { habitatSuitabilityInfrastructureImpact } \\
& -\{\text { condition }+[\text { conditionRateChange } \times(\text { occupancyDays }-1)]\})
\end{aligned}
$$

d. If

$$
\begin{gathered}
\{(\text { condition })-[(\text { occupancyDays }-1) \times \text { conditionRateChange }]\} \\
>\text { habitatSuitabilityInfrastructureImpact }
\end{gathered}
$$

then

$$
\begin{aligned}
(\{(\text { condition })- & {[(\text { occupancyDays }-1) \times \text { conditionRateChange }]\} } \\
& - \text { habitatSuitabilityInfrastructureImpact }) \geq \text { conditionRateChange }
\end{aligned}
$$

else

condition $=$ habitatSuitabilityInfrastructureImpact

e. If

$$
\begin{aligned}
(\{(\text { condition })- & {[(\text { occupancyDays }-1) \times \text { conditionRateChange }]\} } \\
& - \text { habitatSuitability InfrastructureImpact }) \geq \text { conditionRateChange }
\end{aligned}
$$

then

condition $=$ condition $-($ occupancyDays $\times$ conditionRateChange $)$

else

condition

$$
\begin{aligned}
& =[\{\text { condition }-[\text { conditionRateChange } \times(\text { occupancyDays }-1)]\} \\
& -(\{\text { condition }-[(\text { occupancyDays }-1) \times \text { conditionRateChange }]\} \\
& - \text { habitatSuitabilityInfrastructureImpact })]
\end{aligned}
$$

\section{Reproduction}

The following principles provide the basis for the model's representation of reproduction:

- Probability of producing offspring is a deterministic function of condition;

- Production of offspring is a stochastic event; and

- Number of offspring produced is a deterministic function of condition.

Our model assumes that every adult and yearling female sage-grouse that attends a lek will mate and subsequently initiate a nest. Nest success was calculated based on a conditionbased probability of success described by the logistic function shown in Figure 12 that had been 


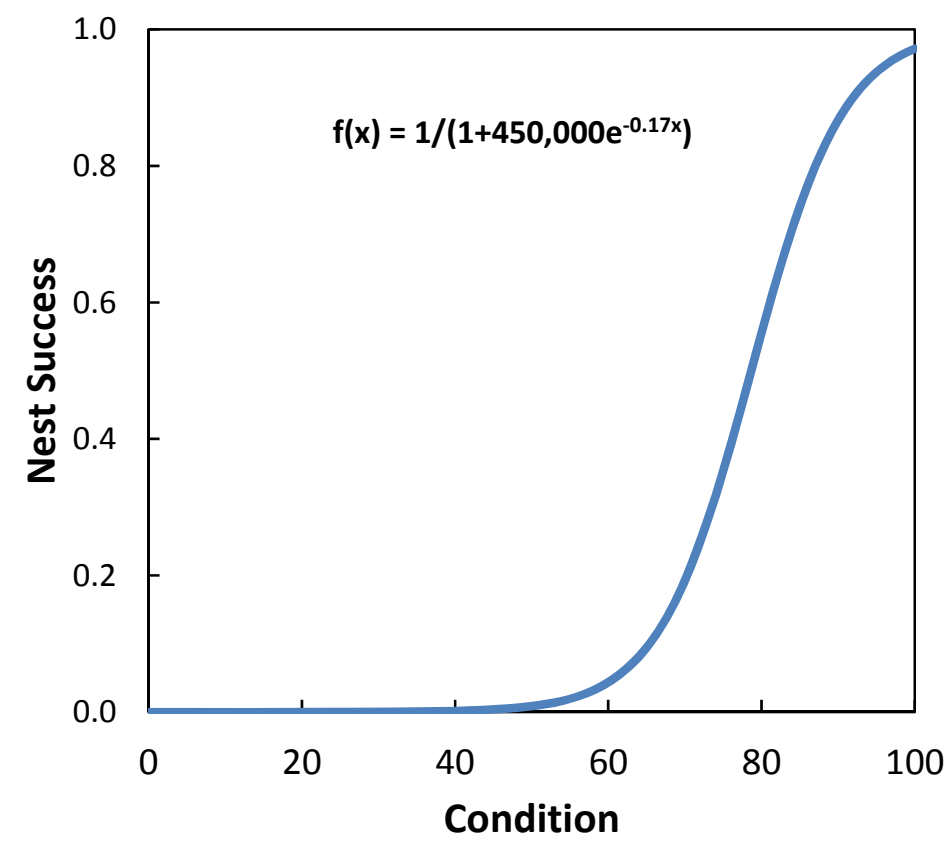

FIGURE 12 Modeled Relationship between Sage-Grouse Condition and Nest Success

fitted to a mean reproductive probability of 35\% (Connelly et al. 2004; Holloran 1999), and assumed by us to correspond to a female with a condition value of 75 .

The production of offspring was modeled stochastically by comparing a pseudo-random number to the probability of nest success; if the random number was less than the probability of nest success, then the individual would produce offspring. For successful nests, the number of offspring produced (clutch size) was determined using the logistic function shown in Figure 13that had been fitted to a mean clutch size of 7.4 eggs (Connelly et al. 2004), and assumed by us to correspond to a female with a condition value of 75 .

\section{Movement}

The following principles provide the basis for the model's representation of movement:

- Life history dictates movement between seasons;

- Daily movement is not represented; and

- Value of condition remains constant during movement between seasonal habitats. 


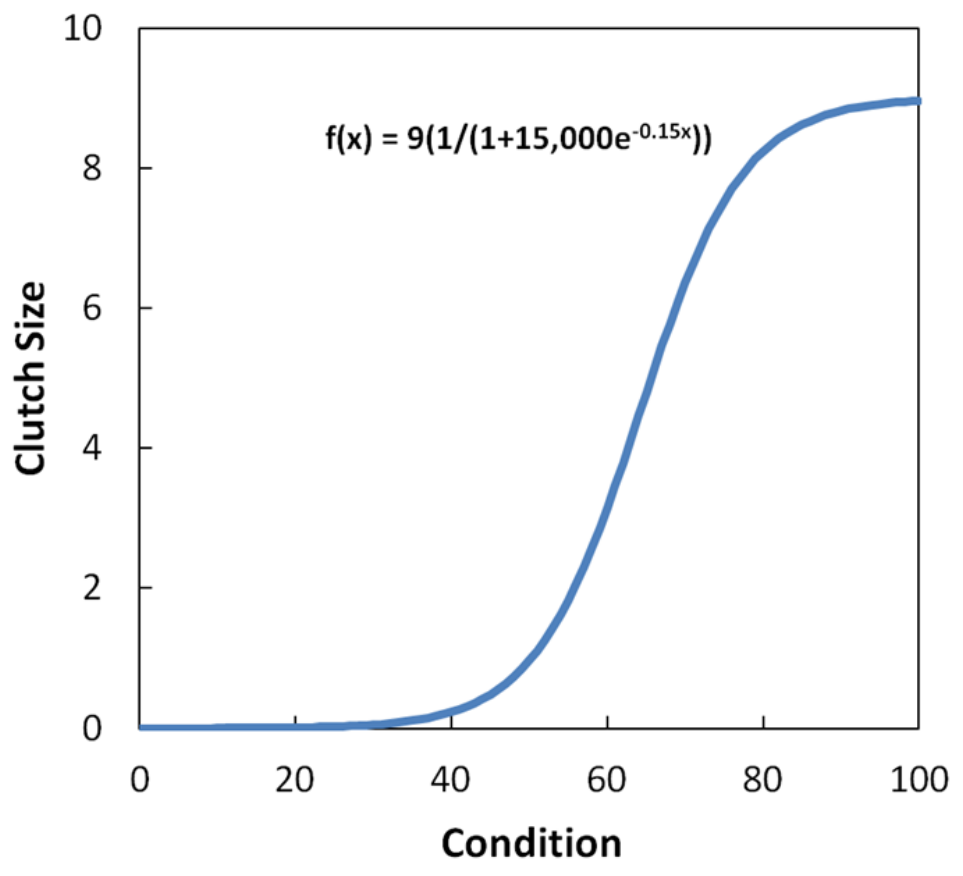

FIGURE 13 Modeled Relationship between Sage-Grouse Condition and Clutch Size

Spatial and temporal movement between seasons in the model was based on the life history of sage-grouse; chicks and juvenile sage-grouse are assumed to be completely dependent upon their mother and therefore imitate their mother's movement behavior. Daily movement is not represented in the model based on the assumption that a cell represents the center of the occupant's home range throughout a given season. The selection of seasonal habitat corresponds to the relationship between habitat characteristics, assumed maximum travel distances (Table 5), and the time of year.

Individuals were modeled to travel at a rate of $1 \mathrm{~km} /$ day between seasons, with the exception of the transition from summer to winter habitat ( $0.3 \mathrm{~km} /$ day) (Connelly et al. 2004). The initial movement of individuals between seasons was stochastically determined within a given 14-day interval. The modeled value of condition remained constant when individuals moved between seasonal habitats.

\section{Condition}

The following principles provide the basis for the model's representation of condition:

- Condition affects dominance, habitat selection, survivorship, and reproduction; 
TABLE 5 Modeled Maximum Travel Distances of Sage-Grouse between Seasons (seasonal period in parentheses)

\begin{tabular}{lll}
\hline Seasonal Habitat Destination & \multicolumn{1}{c}{ Males } & \multicolumn{1}{c}{ Females } \\
\hline & & \\
Nest & Not applicable & $5 \mathrm{~km}$ (March-April) \\
Lek & $10 \mathrm{~km}$ (March-April) & $5 \mathrm{~km}$ (April) \\
Nest & Not applicable & $5 \mathrm{~km}$ (April-May) \\
Early brood-rearing & Not applicable & $10 \mathrm{~km}$ (June) \\
Summer & $10 \mathrm{~km}$ (June-July) & $10 \mathrm{~km}$ (June-July) \\
Winter & $10 \mathrm{~km}$ (December) & $10 \mathrm{~km}$ (December) \\
\hline
\end{tabular}

- Habitat suitability is the primary determinant of condition; and

- Occupancy duration is a limiting factor of condition change.

Sage-grouse behavior was modeled utilizing an indirect fitness-seeking behavior based on the assumption that individuals act in a manner that maximizes their value of condition. This approach assumes that future condition increases with the increasing value of condition; therefore condition is an acceptable model of expected condition.

The calculation of condition included the impact of infrastructure on the value of habitat suitability as well as the competition for habitat resources associated with the occupancy of a given cell. The value of condition was modeled to improve or decline toward the value of habitat suitability with a constant rate of change based on the difference between the bird's starting condition and the cell suitability value.

The following steps describe the method used to calculate the value of condition as a daily expression of expected condition:

1. The baseline habitat suitability value of the home range is based on the spatial average filter that was employed in the formulation of the HSI maps (Section 4).

2. The impact of infrastructure on the value of habitat suitability was calculated as described previously under "Infrastructure Cells."

3. The impact of competition on the value of habitat suitability was modeled. A competition factor (provisionally set to 0.5 ) was applied as a percentage reduction to the habitat suitability value of an occupied cell within an individual's seasonal home range and the weighted average value of the cells within the home range was determined. Thus, if a bird's home range included the home range center of another sage-grouse, the HSI value of the cell occupied by the competitor was proportionally reduced by $50 \%$. The habitat suitability of the first bird was then recalculated using the following formula: 


$$
\begin{aligned}
& \text { habitatSuitabilityCompeteImpact } \\
& \qquad \begin{array}{l}
\times\{\text { habitatSuitabilityBaseline } \\
\times(\text { homeRangeCount }- \text { homeRangeCompeteCount })] \\
+(\text { habitatSuitabilityBaseline } \times \text { competeFactor } \\
\times \text { homeRangeCompeteCount })\} / \text { homeRangeCount }
\end{array}
\end{aligned}
$$

4. The cumulative impact of infrastructure and competition on the value of habitat suitability was calculated. The two equations were combined as follows:

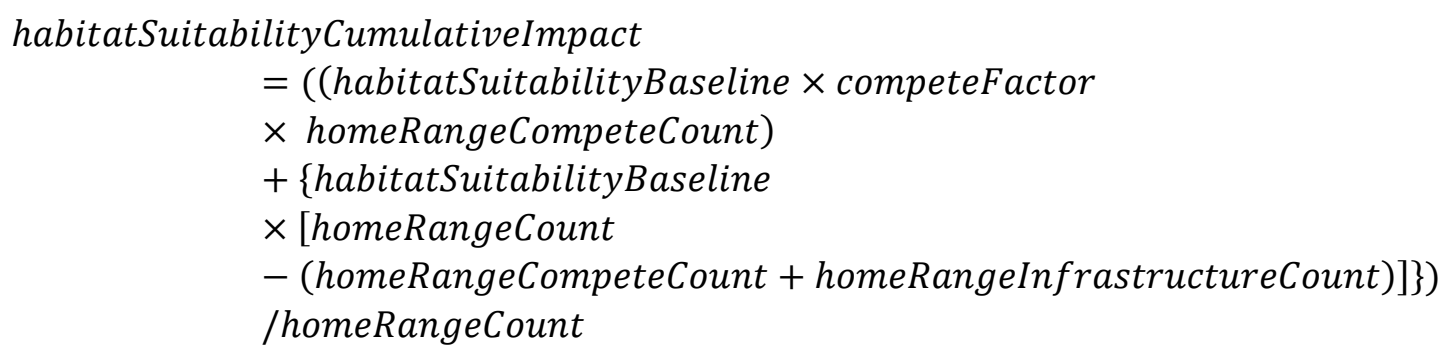

5. The rate of change of the value of condition was calculated. The absolute value of the difference between the value of habitat suitability (accounting for the cumulative impact of infrastructure and competition) and the value of condition divided by the theoretical maximum difference expressed as a number of days of occupancy (provisionally set to 100) was determined:

$$
\begin{aligned}
& \text { conditionRateChange } \\
& \qquad=\text { abs }[(\text { habitatSuitabilityCumulativeImpact }- \text { condition }) / 100]
\end{aligned}
$$

6. The daily value of condition was calculated. A piecewise function was applied as the value of condition tends toward the value of habitat suitability:

a. If

abs (habitatSuitabilityCumulativeImpact - condition $) \geq($ conditionRateChange)

then

condition $=$ condition + conditionRateChange

b. If abs (habitatSuitabilityCumulativeImpact - condition $)<($ conditionRateChange $)$

then condition $=$ condition $+($ habitatSuitabilityCumulativeImpact - condition $)$

c. If conditionRateChange $=0$ 
then

condition $=$ habitatSuitabilityCumulativeImpact

An example of the rate of condition change and its dependence on the difference between the starting condition of the sage-grouse and the HSI value of the habitat it occupies is shown in Figure 14.

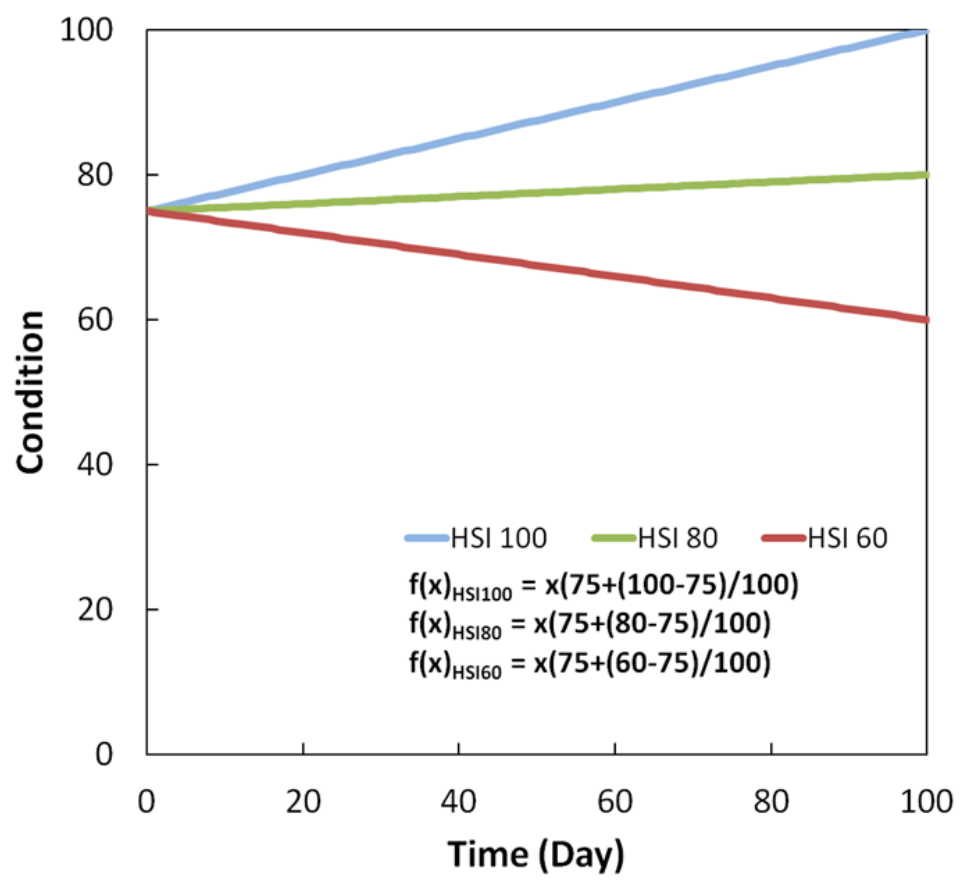

FIGURE 14 Modeled Relationship between Sage-Grouse Condition and Length of Habitat Occupancy for a SageGrouse with a Starting Condition of 75 in a Seasonal Home Range with HSI Values of 60, 80, and 100

\section{Mortality}

The following principles provide the basis for the model's representation of mortality:

- Probability of survival is a deterministic function of condition and infrastructure impact on survivorship;

- Mortality is a stochastic event; and

- Chicks and juveniles are completely dependent upon their mother for survival.

Published annual survivorship probabilities (Holloran 1999; Connelly et al. 2004) for each age-sex class (adult and yearling males $=0.529$, adult and yearling females $=0.787$, 
juvenile and chicks $=0.6$ ) were transformed by a constant function assuming the published survival values corresponded to occupancy of a habitat with a HSI value of 75.

Chicks and juvenile sage-grouse were assumed to be completely dependent upon their mother for survival and therefore die if their mother dies. A scaled daily probability of survival was calculated for each individual as a deterministic function of condition and infrastructure impact on survivorship:

$$
\begin{aligned}
& \text { survivalProbability } \\
& =[\sqrt[365]{(\text { survivorshipScale } \times \text { condition })}] \\
& \times(\sqrt[365]{\{\text { survivorshipInfrastructurelmpact } \times[1+(\text { mitigationfactor } \times .01)]\}})
\end{aligned}
$$

where survivorshipScale is equal to the corresponding observed survivorship probability transformed by the multiplicative inverse of the assumed average habitat suitability value (i.e., 1/75). Mortality was modeled stochastically by comparing a pseudo-random number to the survival probability; if the random number was greater than the probability of survival, then the individual died. The modeled probability of surviving 90 days as related to condition is shown in Figure 15.

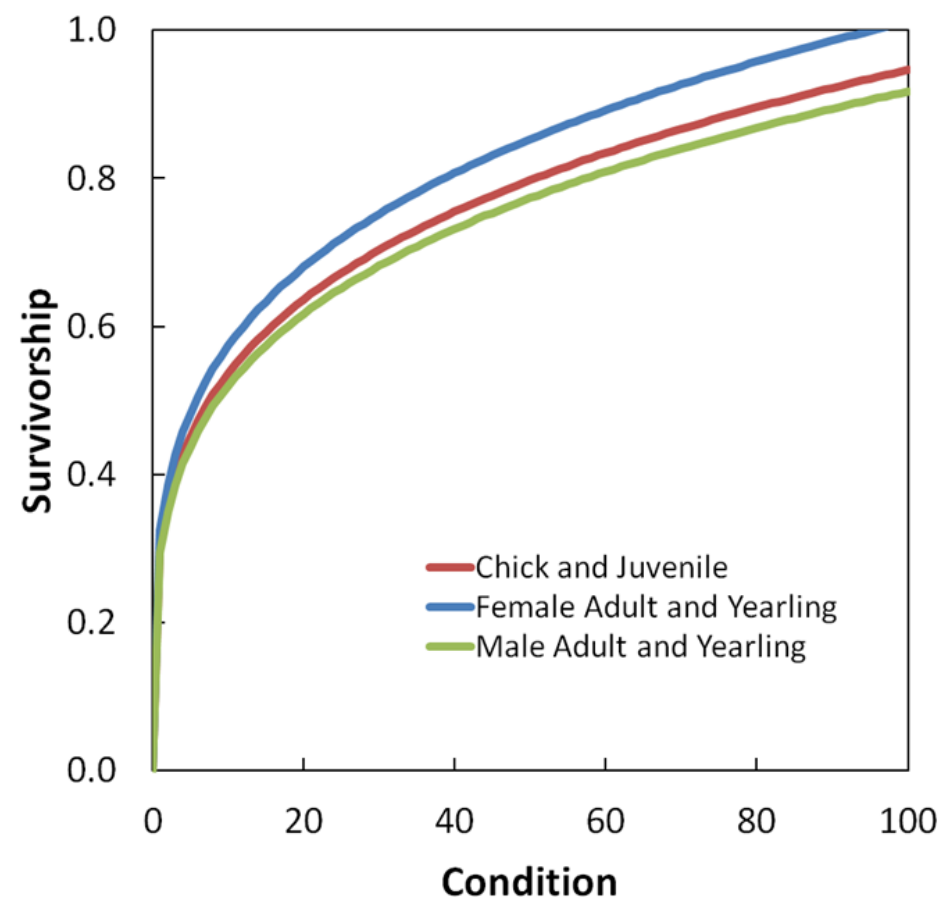

FIGURE 15 Modeled Relationship between Sage-Grouse Survivorship and Condition 


\subsubsection{Initialization}

The following methods were employed in the initialization of the objects for each simulation. The pseudo-random number generator used for all stochastic processes in the IBM was initialized with a random number seed (randomSeed) defined by input data supplied prior to initialization.

\subsubsection{Cells}

We set the lek count to 92 based upon our estimate of total sage-grouse population size in Albany County (Table 6), a starting male to female sex ratio of 1:1 (Atamian [2007] in Connelly et al. 2011), and a mean male lek attendance in Wyoming of 27.92 males per lek (Doherty et al. 2010b). The model begins by reading in the habitat characteristics that remain constant throughout the simulation (the value of habitat suitability for each of the five seasons) from input files. The lek locations were assigned to the cells with the highest lek suitability values (taking into account the effect of existing infrastructure on habitat suitability) and separated by a minimum of $2.5 \mathrm{~km}$ in all directions (Dalke et al. 1963). Variables that depend on time-series input (infrastructure location, proximity count, and impact on the value of habitat suitability) were then set with the initial input data on the first day of scenario implementation.

\subsubsection{Sage-Grouse}

We set the starting population of adult sage-grouse at 5,000 on the basis of our estimation of total population (Table 6) and used a starting sex ratio of 1:1. Primary sources for determining the initial population size are USFWS (2010) and Doherty et al. (2010b). Total sage-grouse population in Wyoming was reported as 207,560 (USFWS 2010). Proportions of area for each breeding-density quartile (top $25 \%$ densely population area, next $25 \%$, and so on) within Albany County was computed relative to those within Wyoming based on the information extracted from Doherty et al. (2010b). Population size for each breeding-density quartile was computed by weighting each $25 \%$ of total population by the corresponding proportion. Finally, population sizes of the four quartiles were summed to obtain an estimate of sage-grouse population size in Albany County $(5,120)$. We tested several different initial population sizes at baseline conditions to examine the robustness of the model with respect to the initial population size.

The placement of males in winter habitat (each simulation began on January 1 of year 1) with a minimum HSI value (set to 75) and positioned within $10 \mathrm{~km}$ (maximum travel distance) of a lek was stochastically determined. The placement of females in winter habitat with a minimum HSI value (also set to 75) and positioned within $5 \mathrm{~km}$ (maximum travel distance) of a cell with a minimum nest HSI value (set to 75) that was in turn within $5 \mathrm{~km}$ of a lek was similarly determined. After all sage-grouse had been placed, the model calculated the initial condition of each individual, taking into account the impact of existing infrastructure on habitat suitability, as well as competition. 
TABLE 6 Basis of Sage-Grouse Population Estimate for Albany County

\begin{tabular}{|c|c|c|c|c|c|}
\hline \multirow[b]{2}{*}{$\begin{array}{c}\text { Population Density } \\
\text { Quartile }^{\mathrm{a}}\end{array}$} & \multicolumn{2}{|c|}{ Wyoming } & \multicolumn{3}{|c|}{ Albany County } \\
\hline & Area (ha) & $\begin{array}{l}\text { Number of } \\
\text { Individuals } \\
\text { in Quartile }\end{array}$ & Area (ha) & Proportion & $\begin{array}{l}\text { Number of } \\
\text { Individuals } \\
\text { in Quartile }\end{array}$ \\
\hline First $(0-25 \%)$ & $1,307,198$ & 51,890 & 33,530 & 0.026 & 1,331 \\
\hline Second $(25-50 \%)$ & $1,716,485$ & 51,890 & 47,237 & 0.028 & 1,428 \\
\hline Third (50-75\%) & $3,828,803$ & 51,890 & 72,602 & 0.019 & 984 \\
\hline Last $(75-100 \%)$ & $4,571,967$ & 51,890 & 121,302 & 0.027 & 1,377 \\
\hline Total Population & & $\begin{array}{c}207,560 \\
\text { (USFWS 2010) }\end{array}$ & & & 5,120 \\
\hline
\end{tabular}

a Adapted from the breeding density quartile in Doherty et al. (2010b).

It is worth noting that the initial population has no memory of the previous year upon which to base its inter-annual site fidelity behavior. Rather, individuals create a memory for each season of the first year of the simulation - selecting the habitat anywhere within the maximum travel distance from its current seasonal location (starting with its initial location) that will provide the highest expected condition without initial regard for the occupancy of higher-ranking individuals or the impact of existing infrastructure on the value of habitat suitability.

\subsubsection{Scheduling}

The IBM employed asynchronous updating of a fixed schedule of actions. The five sagegrouse actions in the model were performed in the following order: habitat selection, reproduction, movement between seasons, condition evaluation, and mortality assessment as described here:

1. Habitat selection was the first action executed in the model due to its significant effect, direct and indirect, on all other actions. Movement between seasons is a result of habitat selection. While the probability of reproduction and the probability of survival are dependent on condition, condition is a function of habitat suitability as determined by habitat selection.

2. Reproduction of females was the second action executed in the model because this determines the number of individuals produced and seasonal habitat use by females.

3. Movement between seasons preceded condition evaluation based on the assumption that the value of condition remains constant throughout movement between seasons. 
4. Condition evaluation preceded mortality assessment because the probability of survival is a function of the value of condition.

5. Mortality assessment was the final action executed in the model because it is dependent, directly or indirectly, on all of the other actions.

Each individual completes the first three actions (habitat selection, reproduction, and movement between seasons) one after another, followed by the next individual in descending order of the condition-based hierarchy. Condition evaluation is then completed by all individuals followed by mortality assessment. Females were given priority in conducting condition evaluation and mortality assessment because of the dependence of chicks and juvenile sagegrouse on their mother's behavior. Detailed daily scheduling of actions in the model is presented in Figure 16.

\subsubsection{Model Output}

The IBM produces output from both individual-level and population-level perspectives. Monitors in the interface can be opened to observe and control variables, and a variety of summary optional text and video output files can be created. A combination of graphical displays and statistics provide information on the state of individuals on a daily basis, as well as the overall final results representing population conditions spanning the entire simulation.

The IBM provides a graphical display of the habitat cells and the corresponding location of sage-grouse as the model is executed. Within this display, agent monitors can be opened for the purpose of testing and understanding the model. These windows supply both the values of all the variables for a particular agent and a close-up view of the agent and its immediate surroundings. Below the agent variable area there is a command center that allows the entry of code to be executed only by this agent. This was the method used to test the substructure of the model.

Summary population statistics are generated from the IBM and reported via text file output. These statistics include age-sex class specific population trajectories, birth rate, death rate, rate of natural increase, life expectancy, and age distribution.

The IBM provides the option of recording a QuickTime movie of the graphical display (or the entire model interface) to be used in understanding patterns of sage-grouse habitat use. Variable frame rates allow for time compression and file size management. 


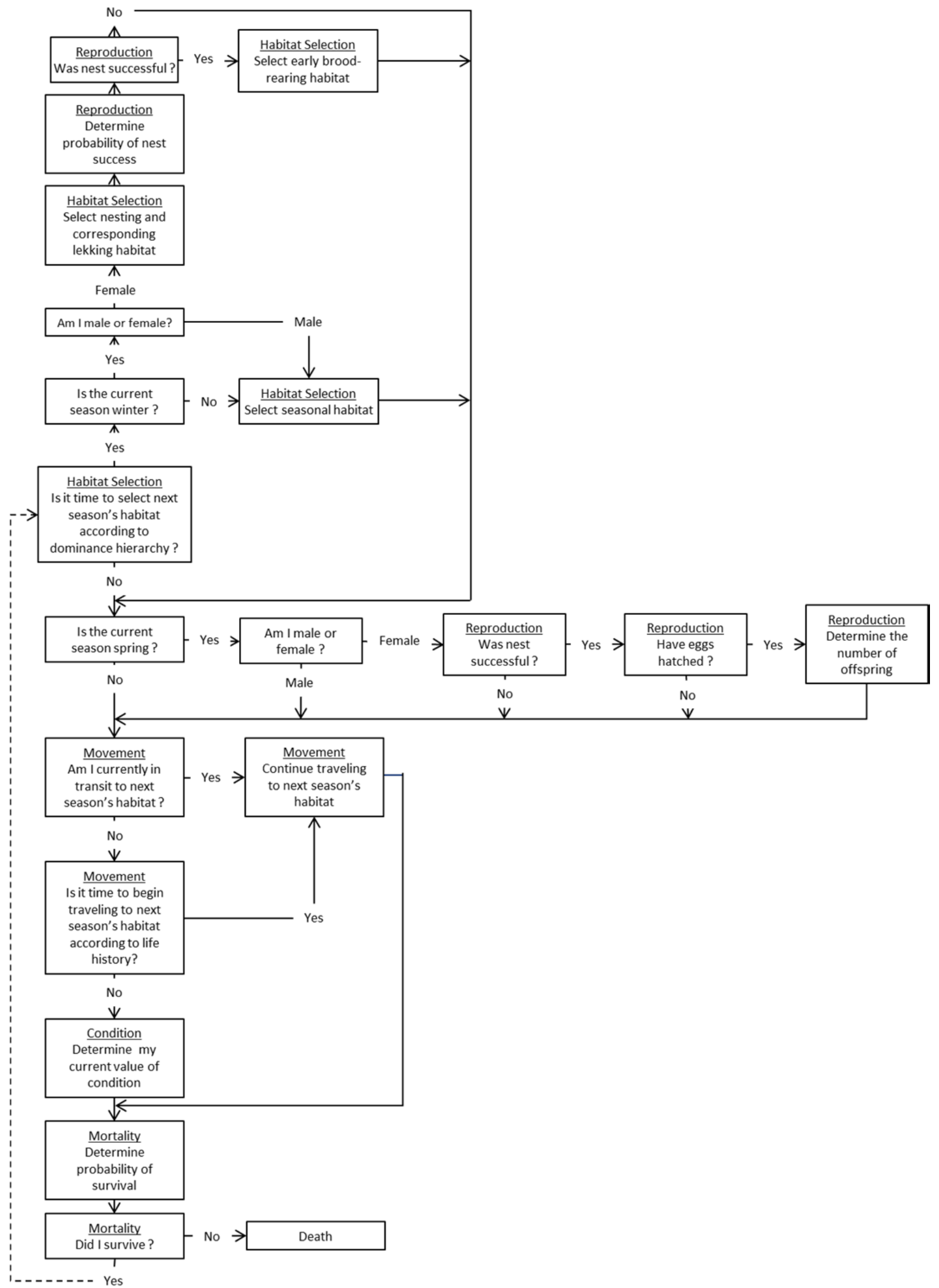

FIGURE 16 Scheduled Daily Actions of Individual Sage-Grouse in the IBM 


\section{INDIVIDUAL-BASED MODEL PERFORMANCE AND APPLICATION}

It is important to recognize that our model is in the early stages of development and that the predicted effects we describe in this section cannot be interpreted as real predictions of the effects of wind energy development on real sage-grouse populations. Nor can our description of baseline sage-grouse population size and distribution be interpreted as the actual distribution and size of this population in the study area. We intend this discussion to show how the model could be used to analyze population-level effects of planned or proposed development.

Seasonal (spring immediately after lekking, summer, and winter) population distributions in three different years $(5,15$, and 30 years after model initialization) are shown in Figure 17. Overall, there is no major difference in seasonal sage-grouse distributions across seasons and years, except shortly after initialization. In this early distribution, several population clusters are located in the central and northern portion of the study area, but there are no clusters in the southern portion of the study area. After model initialization, sage-grouse are more sparsely distributed within clusters over a slightly larger spatial extent than in later years. The initial population clusters located in the west-central part of the study area are no longer present in year 5, even though one shows a very high initial concentration. The loss of these population clusters may be due to the lack of high-quality summer range in this area (Figure 8 ) and to the concentration of existing infrastructure in the area (Figure 11).

The model predicted that sage-grouse would exhibit similar spatial patterns in different seasons and years. In general, three distinct clusters were predicted: one in the northwestern corner and two near the center of the study area; of the latter, one is located west to northwest of Wheatland Reservoir Number 3 and the other to the east of Wheatland Reservoir Number 2 (Figure 17). Despite these similarities, the model predicted that sage-grouse would utilize slightly different areas in the spring than in other seasons. This pattern suggests the unique habitat requirements for food and shelter during spring seasons, which is supported by a number of past studies (Connelly et al. 2004; Holloran 1999). Sage-grouse population clusters in summer were qualitatively predicted to have higher density than winter in any given year, which is consistent with the findings of Connelly et al. (2004).

The number of adult and yearling sage-grouse broken down by year and season are shown in Figure 18. There are consistent seasonal patterns across years. The largest population size is observed in the springtime after juveniles become yearlings and yearlings become adults. The pronounced population decline from summer to winter can be explained by limited food availability during summer droughts in the region and increased susceptibility to disease and predation due to high population density. This seasonal pattern is consistent with the findings of other studies (Connelly et al. 2004; Walker et al. 2007).

Three scenarios of potential wind energy development were developed to demonstrate the viability of the technical approach and its applicability to evaluating the cumulative effects of wind energy and other developments. The scenarios were patterned after two existing wind energy projects in Albany County - the High Plains and McFadden Ridge Wind Farms (PacifCorp 2011a,b). Characteristics of these wind energy projects that were applied to our 


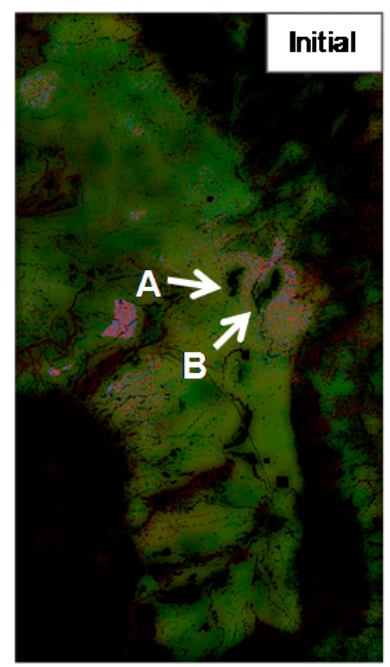
$\Delta$ Male
A Female
Chick
$\Delta$ Male Juvenile
$\Delta$ Female juvenile
$\triangle$ Male yearling
A Female yearling
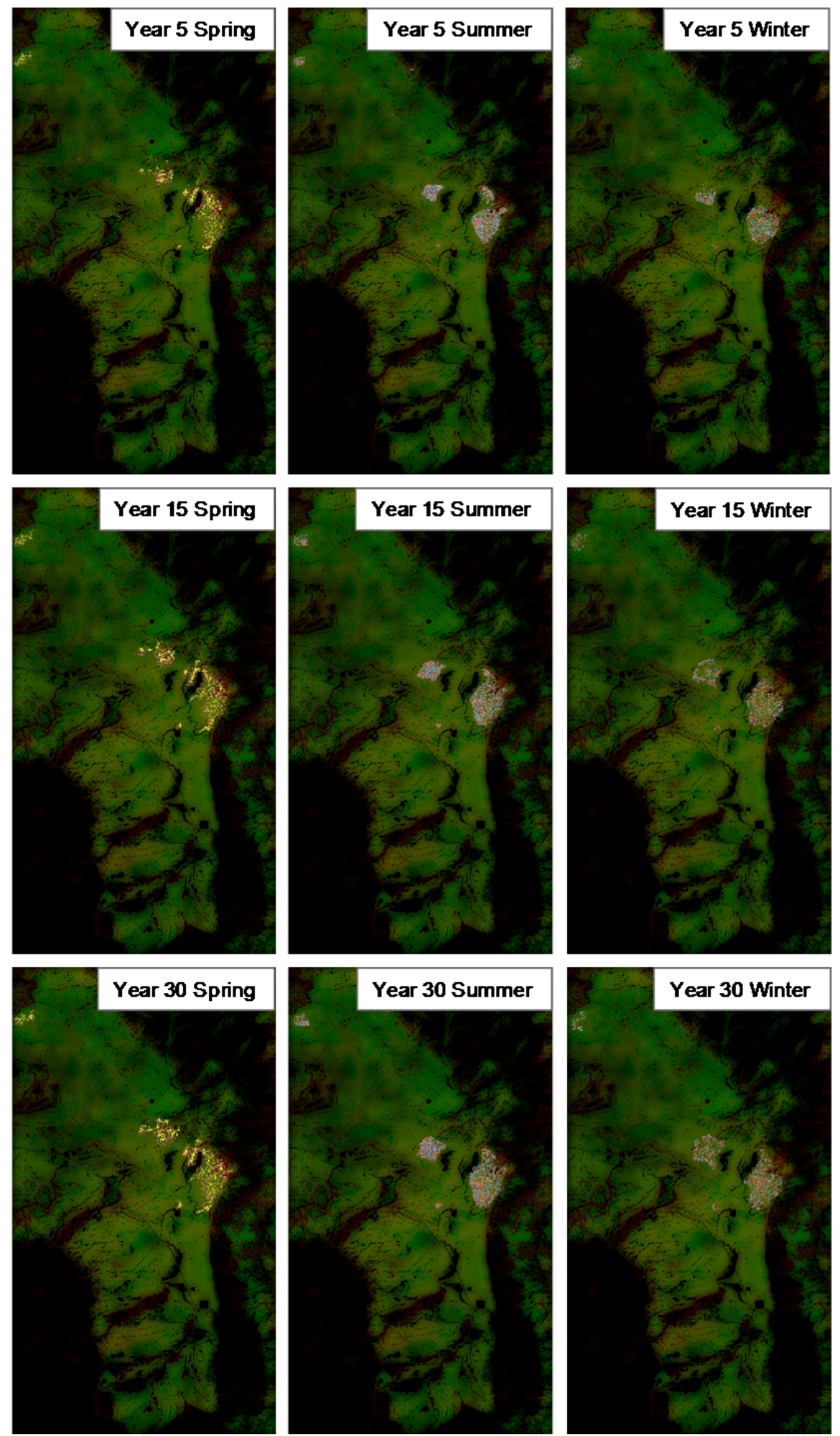

FIGURE 17 Modeled Seasonal Population Distributions under Baseline Conditions after Initialization and in Three Subsequent Years (Wheatland Reservoir Number 3 [A] and Wheatland Reservoir Number 2 [B] are indicated on the initial population map for geographic reference.) 

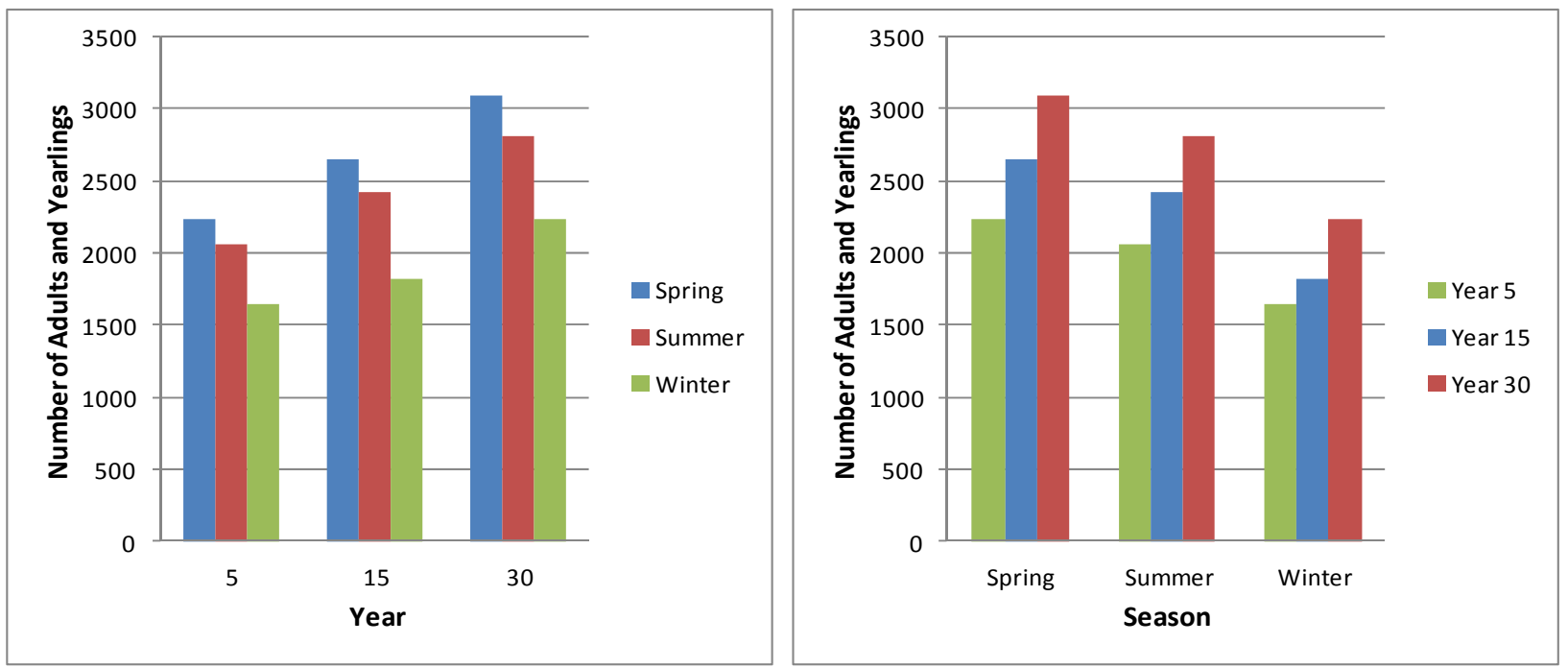

FIGURE 18 Modeled Number of Adult and Yearling Sage-Grouse under Baseline Conditions by Year and Season

development scenarios include the following: topography (slope $\leq 7 \%$ ), wind potential (wind potential class $\geq 5$ ), the number of turbines ( 85 turbines total), and land area requirements (approximately $12-17 \mathrm{~km}^{2}$ ).

Utilizing the slope layer generated from DEM and the wind potential map (NREL 2009), areas that meet the criteria of slope and wind-potential criteria were spatially identified as candidates for potential future wind development. A sage-grouse distribution map that was generated from an earlier run of the IBM was considered when placing hypothetical wind developments and was used as the baseline condition. Within hypothetical development areas, the following three scenarios with different spatial configurations (footprints) and proximity to undisturbed sage-grouse populations were selected (Figure 19):

- Scenario 1: a fairly linear arrangement of turbines along a ridge adjacent to an area that is used by sage-grouse in winter, spring, and summer;

- Scenario 2: the same location as Scenario 1, but a more compact configuration of turbines; and

- Scenario 3: a comparable footprint configuration to Scenario 1, located in an area used by sage-grouse in spring but not used in winter or summer.

A set of geospatial layers that represents hypothetical wind development was generated for each scenario by adding new wind turbines and access roads to the baseline infrastructure occurrence layers. The entire development of each scenario was divided into three phases over a 3 -year period. These phases represented the sequence of construction as more turbines and needed roads were built in each subsequent year. The infrastructure occurrence and abundance 


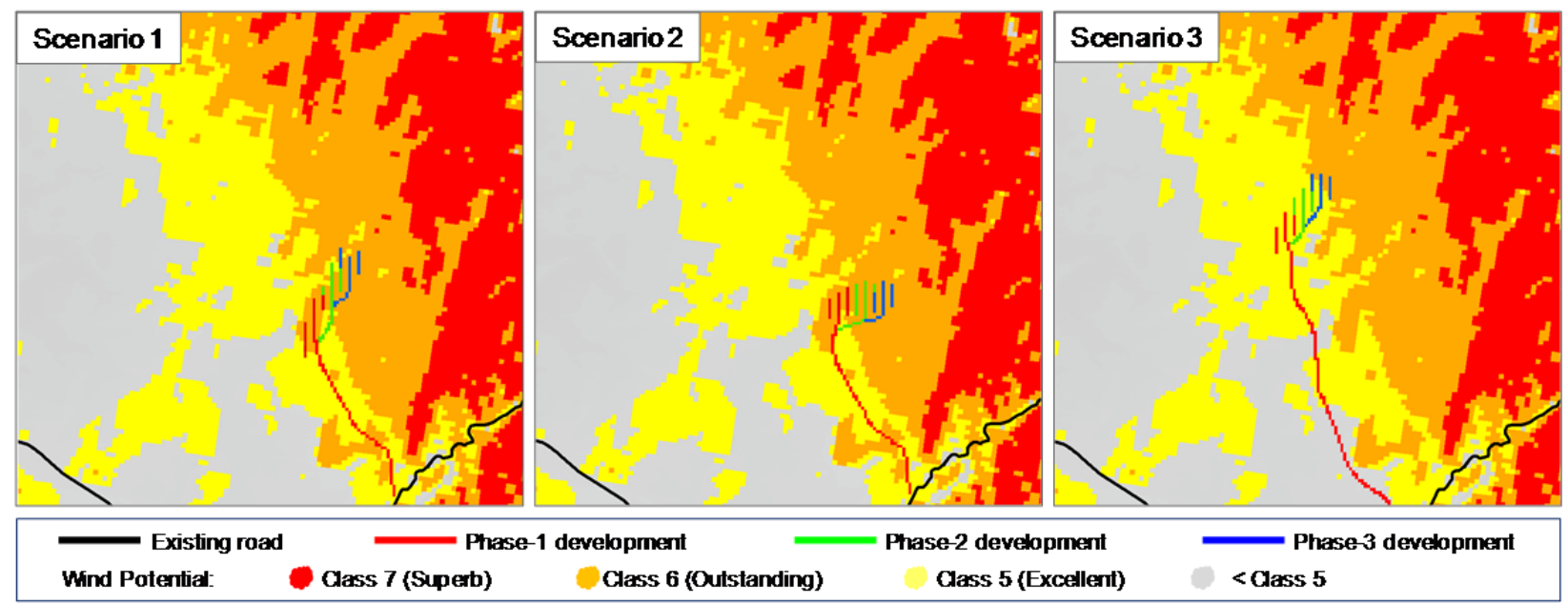

FIGURE 19 Hypothetical Wind Development Scenarios Evaluated with the IBM (Development at each phase includes new wind turbines and access roads.)

layers were then updated for each scenario (Figure 19). Each development scenario was applied on January 1st of Year 27. The second and third phases of development were applied in subsequent years.

The modeled spatial distributions and population trajectories of greater sage-grouse under baseline conditions and three hypothetical development scenarios are shown in Figure 20. The population distribution maps for each scenario show the distribution of modeled individuals immediately after the lekking season of Year 45 (or 16 years after the completion of the 3-year construction). In all scenarios, individual sage-grouse no longer used developed areas because development represents a significant decrease in habitat suitability and imposes a reduction in survivorship. Numbers are also reduced in surrounding areas, presumably because of the effects of infrastructure on survivorship (Figure 11) and habitat suitability.

The decline in population in the first several years of the simulation is in large part a result of the initialization process, which randomly places individuals of the starting population in habitats that have HSI values of at least 75. Since the model starts on January 1, those habitats are all winter habitats, and starting locations are not necessarily within $10 \mathrm{~km}$ of suitable habitats for other seasons. As a consequence, there is typically a pronounced decrease in population size at the beginning of each model run as these individuals die. There can be other factors that initially result in a decrease in numbers (e.g., random effects of crowding), but these are eventually sorted out as surviving individuals adapt to habitat conditions, by moving to areas of higher suitability.

Our model predicted that Scenario 1 and Scenario 2, which are located in the same area, but with a different configuration of turbines, would result in similar population trajectories and spatial distributions during the breeding season, while Scenario 3 (the equivalent configuration to Scenario 1 placed in a different location) would exhibit a very different population-level effect (Figure 20). This may suggest that, at least in these cases, location of development was more 

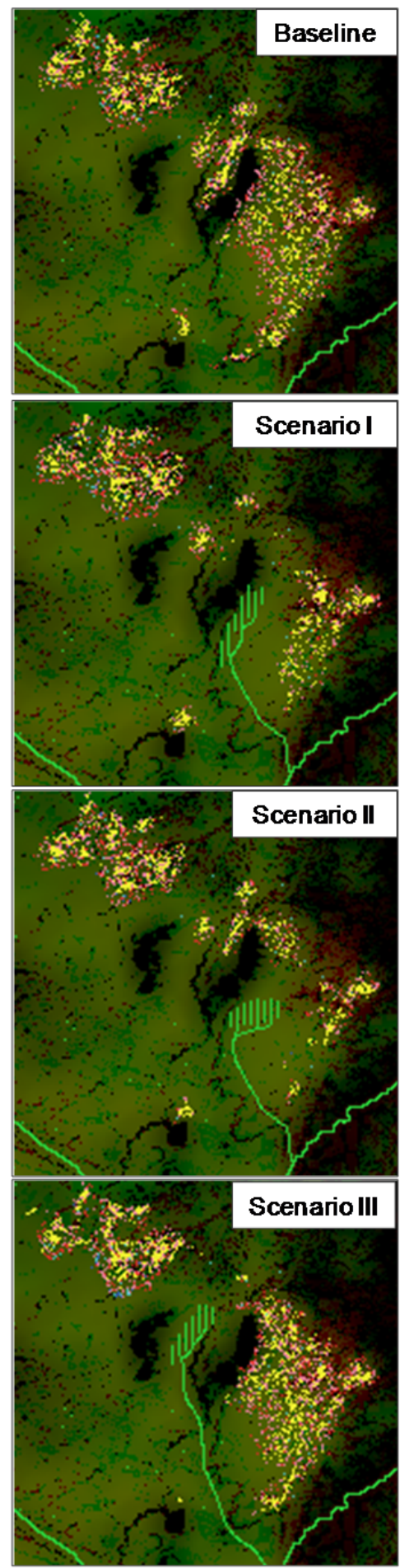
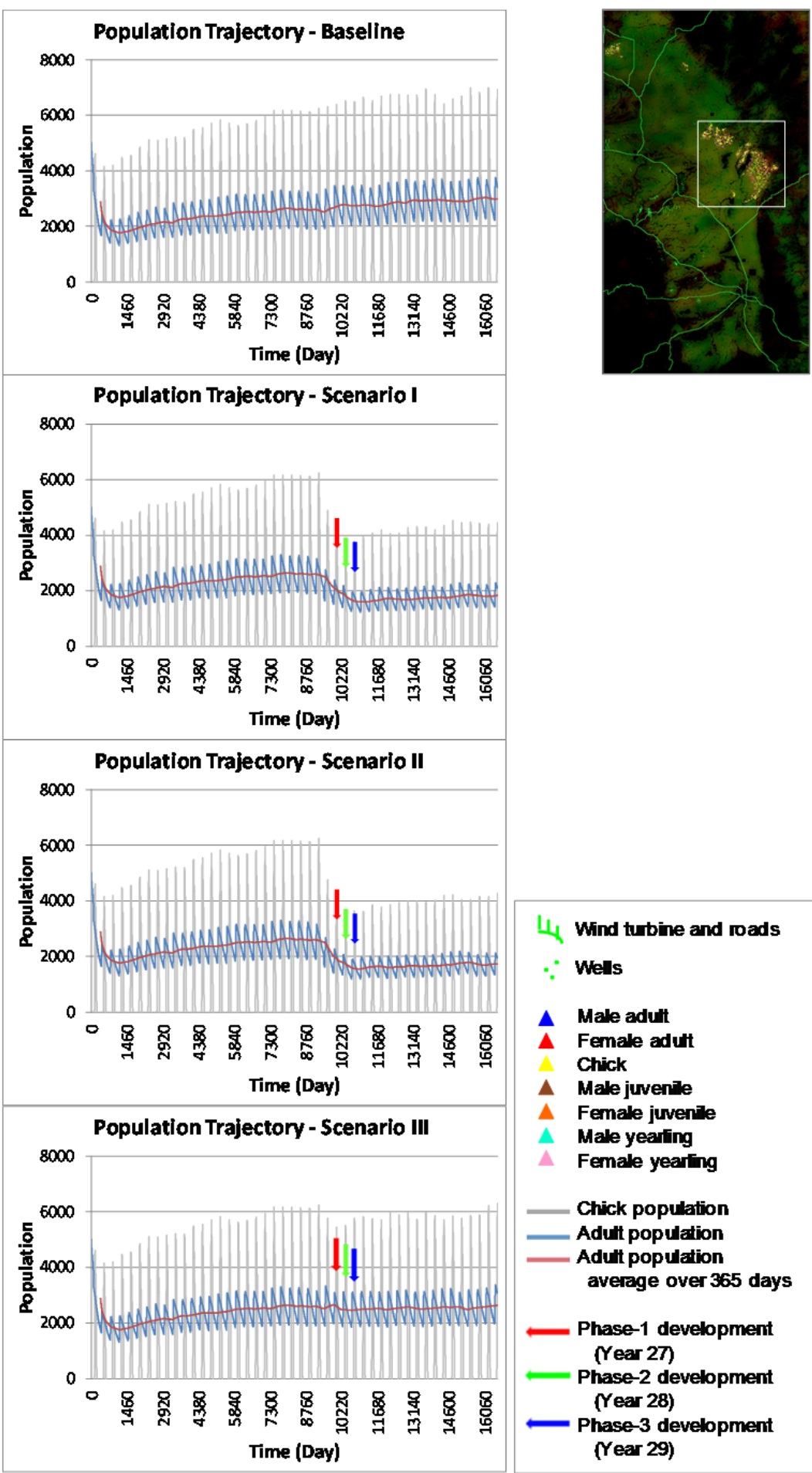

4y Wind tumine and roads

$\because$ Wels

A Male adult

A Female adut

Chick

A Male juvenile

- Female juvenile

A Male yearing

A Female yearing

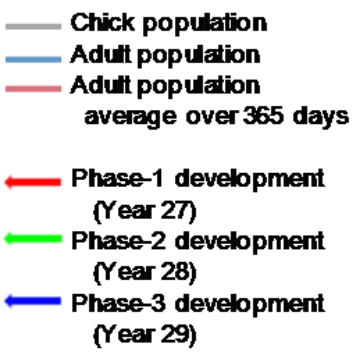

FIGURE 20 Modeled Spatial Distributions and Population Trajectories of Sage-Grouse under Baseline Conditions (no development) and Three Hypothetical Development Scenarios 
important than spatial configuration of infrastructure when determining development effects on sage-grouse. Scenario 3, which was identical to Scenario 1 in terms of footprint configuration, but was located on the other side of Wheatland Reservoir 2, also predicted that sage-grouse would no longer use habitats within and in close proximity to the footprint of Scenario 3 during the spring (Figure 20). However, the population trajectory indicated a noticeably lower impact on total population.

The model predicted some unexpected effects outside of the footprints of Scenarios 1 and 2. The area between Wheatland Reservoirs 2 and 3 (see Figure 17 for the locations of these reservoirs) was predicted to be occupied by sage-grouse during spring under baseline conditions (Figure 20). The model predicted that development under Scenarios 1 and 2 resulted in this area located at the western periphery of Wheatland Reservoir 2 not being used to the same extent during spring after development, even though the area was on the other (northwest) side of the reservoir, away from the development. Based on the qualitative assessment of a time series of sage-grouse distribution maps shown in Figures A-1 through A-3 and a quantitative comparison of the adult and yearling sage-grouse population size over an abbreviated five year span before, during, and after the proposed development shown in Figure 21, the development within highly suitable winter and summer habitat along the eastern periphery of Wheatland Reservoir 2 appeared to impose an indirect impact on the sage-grouse's use of spring habitat along the western periphery of the reservoir. Loss of this portion of the population, together with that portion within the project footprint, produced an approximately $40 \%$ decrease in the modeled population of the study area.

Under Scenario 3, development occurred between the reservoirs and resulted in this same area no longer being used in spring; however, there was a much less dramatic predicted effect on overall population size (approximately 15\% reduction initially with almost complete rebound in subsequent years; Figure 20). The sage-grouse distribution maps, along with the population size comparison, indicate that the development of Scenario 3 is located in a area of low sage-grouse concentration during the winter as well as the summer and therefore appeared to have a minimal impact on the sage-grouse's use of spring habitat on the eastern side of Wheatland Reservoir 2. The three scenarios suggest that the population "evolves" as individuals directly affected by development die, and do not pass their behavior (affinity to these sites) on to next generation through reproduction. The relative abundance of highly suitable spring habitat in close proximity to highly suitable winter and summer habitats along the eastern periphery of Wheatland Reservoir 2 accounts for the significant reduction in population following Scenario 1 and Scenario 2 and the minimal reduction in population following Scenario 3. These scenarios suggest the potential applications of the model in assessing the importance of the integration of all seasonal habitats and the impact of wind energy development on habitat suitability and the life history of the greater sage-grouse. 

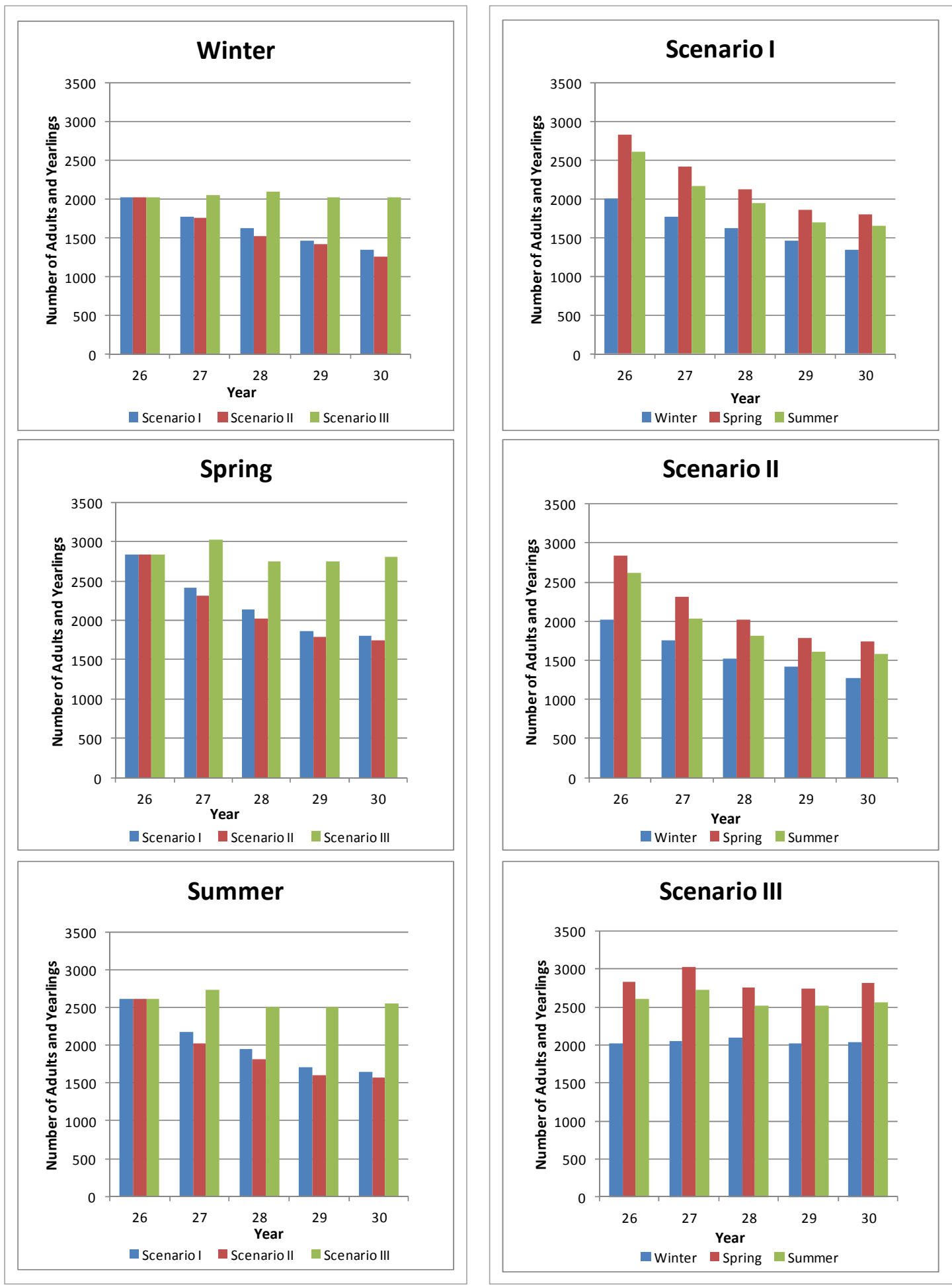

FIGURE 21 Modeled Number of Adult and Yearling Sage-Grouse under Three Hypothetical Development Scenarios over 5 Years (a year before, during, and a year after the development) (Differences in population change across scenarios by season [first column of figures] and differences in population change across seasons by scenario [second column of figures].) 


\section{SUMMARY AND CONCLUSIONS}

Achieving the national goal of $20 \%$ of energy being produced by wind by 2030 will require extensive development of wind energy within the next several years. It is inevitable that this level of development will result in some conflicts with ecological and other environmental resources. To address the need for an approach to evaluate cumulative impacts on critical wildlife habitats, we developed a landscape-based modeling framework for populations of the greater sage-grouse in Albany County, Wyoming. We gathered information about the biology of the greater sage-grouse, including life history, behavior, habitat preference, and impacts of infrastructure on survivorship and habitats, from the literature. We developed models to estimate seasonal habitat suitability, infrastructure effects, habitat selection, movement, condition change, competition, reproduction, and survivorship. We evaluated hypothetical wind energy development scenarios based on existing wind farms in the region to demonstrate the viability of our technical approach and its applicability to evaluating the cumulative effects of wind energy development.

As stated earlier, it is important to recognize that the effects we describe here are conceptual only and should not be interpreted as real predictions of the effects of wind energy development on real sage-grouse populations. We have developed this model as a proof-ofconcept to show the potential for such a tool to predict results that follow from simple and realistic processes of individual responses to conditions and change, but that are unexpected and that may not be predicted if simple assumptions about effects are applied. Such an approach is particularly important for a species such as the greater sage-grouse that has a complex life history and uses different habitats at different times of the year.

According to our HSI maps, suitable seasonal habitats were unevenly distributed across the study area. Areas with high habitat suitability were mostly concentrated near the center of the study area. While suitable habitats were shown to be available for each life-history stage, habitats suitable for all seasons or life-history stages are limited in distribution and may limit the size and distribution of a non-migratory population that cannot move between and utilize distantly separated seasonal habitats.

Our model has the potential to provide users with valuable insights into the potential impacts of wind development on greater sage-grouse. Information extracted from our model output could be used for planning wind development including the location and configuration of developments and mitigation strategies. The modeled results from the three development scenarios we tested suggest impacts on sage-grouse within development sites and adjacent areas, and that the specific location of development within concentration areas is very important when all else is equal. The difference in modeled effects on sage-grouse populations and distribution among scenarios demonstrates the importance of considering all seasonal habitats of sage-grouse when planning wind energy development.

Our model also could be used to test effects of land use changes that are not associated with wind energy development (e.g., conversion of sagebrush habitat to agriculture), as well as compensatory mitigations (e.g., paying landowners not to burn or restoring degraded sagebrush 
areas) in adjacent or other areas. This would be accomplished by reflecting these changes in the HSI values assigned to affected areas. Knowing the timeframe over which changes would occur would allow us to treat this in a temporally realistic fashion.

Our model could be used to evaluate the effects of projects on population viability over an extended timeframe (e.g., decades or centuries) by using realistic starting populations and distributions. Once fully developed, this model could allow stakeholders to assess cumulative impacts of proposed wind and other energy development on the sage-grouse early in the planning and siting process, identify appropriate mitigation strategies if necessary, and avoid or reduce potentially lengthy and costly project delays. In addition, the model could be used to identify (1) existing "hotspots"-areas that are of particular importance or vital to the species; (2) the effect of various perturbations (habitat degradation and fragmentation) on population viability; (3) limits to development; (4) areas where development can occur with little consequence; and (5) adaptive management strategies. The model also provides a framework that could be adapted and applied to other regions with high wind potential and species that are identified as being at risk from wind development.

\section{LIMITATIONS AND FUTURE STUDIES}

Our prototype IBM is built around a number of assumptions to allow us to demonstrate the viability of the technical approach, its applicability to evaluating the cumulative effects of wind energy development, and the issues associated with a broader use of the framework.

For seasonal habitat suitability models, we attempted to develop habitat suitability relationships and maps that were realistic by applying our best knowledge based on published information about greater sage-grouse. More advanced habitat suitability models that integrate over 500 predictor variables are being developed by researchers at the USGS. Once these are available, we will evaluate the potential for their use in our model.

Multiple types of infrastructure are not distinguished in the current IBM, and the impact of all infrastructures on sage-grouse habitat suitability and survivorship are represented as linear functions. As new data are obtained, a better understanding of the separate components of infrastructure and their corresponding levels of impact will allow us to develop a series of more realistic relationships.

The model in its existing form can be used for any non-migratory sage-grouse populations in the upper Great Plains at an approximate county-level scale. Applying the model to larger populations in larger geographical areas is ultimately subject to the limitations of computational efficiency in the software platform. The implementation of the model within a more extensible integrated development environment would facilitate fully scalable applications.

Our future work will focus on (1) conducting preliminary model validation by performing initial sensitivity analyses; (2) modeling multiple infrastructure types as separate components with different impact levels; (3) exploring application of our model to a larger geographical area 
(multi-county or state) using alternative modeling platforms (e.g., Repast); (4) demonstrating the capacity for modeling the effects of other human developments that can affect habitat suitability (e.g., conversion of sage-grouse habitats to agriculture); and (5) demonstrating the ability of the model to project the effects of various mitigation strategies including compensatory mitigations such as habitat improvements and restoration.

\section{REFERENCES}

Aldridge, C.L., and M.S. Boyce, 2007, "Linking Occurrence and Fitness to Persistence: HabitatBased Approach for Endangered Greater Sage-Grouse," Ecological Applications 17:508-526.

Aldridge, C.L., et al., 2008, "Range-Wide Patterns of Greater Sage-Grouse Persistence," Diversity and Distributions 14:983-994.

Beck, J.L., et al., 2006, "Movements and Survival of Juvenile Greater Sage-Grouse in Southeastern Idaho," Wildlife Society Bulletin 34:107-1078.

Beck, T.D.I., 1977, "Sage Grouse Flock Characteristics and Habitat Selection in Winter," Journal of Wildlife Management 41:18-26.

Becker, J.M., et al., 2009, Sage-Grouse and Wind Energy: Biology, Habits, and Potential Effects from Development, technical report, Pacific Northwest National Laboratory.

Berry, J.D., and R.L. Eng, 1985, "Interseasonal Movements and Fidelity to Seasonal Use Areas by Female Sage Grouse," Journal of Wildlife Management 49:237-240.

Bohne, J., et al., 2007, Sage-Grouse Habitat Management Guidelines for Wyoming, Wyoming Game and Fish Department, Cheyenne, WY.

Bradbury, J.W., et al., 1989, "Dispersion of Displaying Male Grouse: II. The Role of Female Dispersion," Behavioral Ecology and Sociobiology 24:15-24.

Connelly, J.W., et al., 2000, "Guidelines to Manage Sage Grouse Populations and Their Habitats," Wildlife Society Bulletin 28:967-985.

Connelly, J.W., et al., 2004, Conservation Assessment of Greater Sage-Grouse and Sagebrush Habitats, unpublished, Western Association of Fish and Wildlife Agencies, Cheyenne, WY.

Connelly, J.W., et al., 2011, "Characteristics and Dynamics of Greater Sage-Grouse Populations," pp. 53-67 in Greater Sage-Grouse: Ecology and Conservation of Landscape Species and Its Habitats. Studies in Avian Biology, No. 38, S.T. Knick and J.W. Connelly (eds.), U.S. Press, Berkeley, CA. 
Crawford, J.A., et al., 2004, "Ecology and Management of Sage-Grouse and Sage-Grouse Habitat," Journal of Range Management 57:2-19.

Dalke, P.D., et al., 1963, "Ecology, Productivity, and Management of Sage Grouse in Idaho," Journal of Wildlife Management 27:810-841.

Doherty, K.E., et al., 2006, "Greater Sage-Grouse Winter Habitat Selection and Energy Development," Journal of Wildlife Management 72:187-195.

Doherty, K.E., et al., 2008, "Greater Sage-Grouse Winter Habitat Selection and Energy Development," Journal of Wildlife Management 72:187-195.

Doherty, K.E., et al., 2010a, "A Currency for Offsetting Energy Development Impacts: HorseTrading Sage-Grouse on the Open Market," PLoS ONE 5:1-9.

Doherty, K.E., et al., 2010b, Mapping Breeding Densities of Greater Sage-Grouse: A Tool for Range-Wide Conservation Planning, technical report, Bureau of Land Management.

Dunn, P.O., and C.E. Braun, 1986, "Late Summer-Spring Movements of Juvenile Sage Grouse," Wilson Bulletin 98:83-92.

Eng, R.L., and P. Schladweiler, 1972, "Sage Grouse Winter Movements and Habitat Use in Central Montana," Journal of Wildlife Management 36:141-146.

Gap Analysis Program, 2010, National Land Cover Gap Analysis Project Metadata. Available at http://lc.gapanalysisprogram.com/landcoverviewer/PDF/LandCover_Metadata.pdf.

Gregg, M.A., et al., 1994, "Vegetational Cover and Predation of Sage Grouse Nests in Oregon," Journal of Wildlife Management 58:162-166.

Grimm, V., and S.F. Railsback, 2005, Individual-Based Modeling and Ecology, Princeton University Press, Princeton, NJ.

Holloran, M.J., 1999, Sage Grouse (Centrocercus urophasianus) Seasonal Habitat Use near Casper, Wyoming, Master's thesis, University of Wyoming.

Holloran, M.J., 2005, Greater Sage-Grouse (Centrocercus urophasianus) Population Response to Natural Gas Field Development in Western Wyoming, Ph.D. thesis, University of Wyoming.

Holloran, M.J., and S.H. Anderson, 2005, "Spatial Distribution of Greater Sage-Grouse Nests in Relatively Contiguous Sagebrush Habitats," Condor 107:742-752.

Holloran, M.J., et al., 2005, "Greater Sage-Grouse Nesting Habitat Selection and Success in Wyoming," Journal of Wildlife Management 69:638-649. 
Homer, C.G., et al., 2008, Multiscale Sagebrush Rangeland Habitat Modeling in Southwest Wyoming, technical report, U.S. Geological Survey.

Hupp, J.W., and C.E. Braun, 1989, "Topographic Distribution of Sage Grouse Foraging in Winter," Journal of Wildlife Management 53:823-829.

Kaiser, R.C., 2006, Recruitment by Greater Sage-Grouse in Association with Natural Gas Development in Western Wyoming, Master's thesis, University of Wyoming.

Naugle, D.E., et al., 2004, "West Nile Virus: Pending Crisis for Greater Sage-Grouse," Ecology Letters 7:704-713.

Novotny, T., 2010, personal communication from Novotny (Bureau of Land Management, Rawlins Field Office, Rawlins, WY) to Y. Hamada (Argonne National Laboratory, Argonne, IL), Aug. 10.

NREL (National Renewal Energy Laboratory), 2009, U.S. Wind Resource Map. Available at http://www.nrel.gov/gis/wind.html. Accessed July 13, 2010.

NWGAP (Northwest Gap Analysis Program), 2010, Wyoming Land Cover Map. Available at http:/gap.uidaho.edu/index.php/gap-home/Northwest-GAP/landcover/download-data-by-state. Accessed July 13, 2010.

Ohmann, J.L., and M.J. Gregory, 2002, "Predictive Mapping of Forest Composition and Structure with Direct Gradient Analysis and Nearest Neighbor Imputation in Coastal Oregon, U.S.A.," Canadian Journal of Forest Research 32:725-741.

PacifiCorp, 2011a, High Plains Wind Project Fact Sheet. Available at http://www.pacificorp.com/content/dam/pacificorp/doc/Energy_Sources/EnergyGeneration_Fact Sheets/RMP_GFS_High_Plains.pdf. Accessed July 1, 2010.

PacifiCorp, 2011b, McFadden Ridge I Wind Project Fact Sheet. Available at http://www.pacificorp.com/content/dam/pacificorp/doc/Energy_Sources/EnergyGeneration_Fact Sheets/RMP_GFS_McFadden_Ridge.pdf. Accessed July 1, 2010.

Railsback, S.F., and V. Grimm, 2011, Agent-Based and Individual-Based Modeling: A Practical Introduction, Princeton University Press, Princeton, NJ.

Sage-Grouse Working Group, 2003, Wyoming Greater Sage-Grouse Conservation Plan, technical report, Wyoming Game and Fish Commission.

Schroeder, M.A., et al., 1999, "Greater Sage-Grouse (Centrocercus urophasianus)," The Birds of North America Online, A. Poole (ed.), Cornell Lab of Ornithology, Ithaca, NY. Available at http://bna.birds.cornell.edu/bna/species/425. 
Schroeder, M.A., et al., 2004, "Distribution of Sage Grouse in North America," Condor 106:363-376.

USFWS (U.S. Fish and Wildlife Service), 2010, "Endangered and Threatened Wildlife and Plants; 12-Month Findings for Petitions to List the Greater Sage-Grouse (Centrocercus urophasianus) as Threatened or Endangered," proposed rules, Federal Register.

USGS (U.S. Geological Survey), 2007, Biology in Your Backyard: Wyoming Highlights. Available at http://biology.usgs.gov/cro/ScienceInYourState/Wyoming/WY-brd.htm.

USGS, 2009, The National Elevation Dataset. Available at http://seamless.usgs.gov/about_elevation.php. Accessed July 15, 2010.

Walker, B.L., et al., 2007, "West Nile Virus and Greater Sage-Grouse: Estimating Infection Rate in a Wild Bird Population," Avian Diseases 51:691-696.

Wallestad, R.O., 1971, "Summer Movements and Habitat Use by Sage Grouse Broods in Central Montana," Journal of Wildlife Management 35:129-136.

Wallestad, R., and R.L. Eng, 1975, "Foods of Adult Sage Grouse in Central Montana," Journal of Wildlife Management 39:628-630.

Wambolt, C.L., et al., 2002, Conservation of Greater Sage-Grouse on Public Lands in the Western US: Implications of Recovery and Management Policies, technical report, Policy Analysis Center for Western Public Lands.

WGFD (Wyoming Fish and Game Department), 2010, Sagebrush/Sage Grouse Management. Sage Grouse Core Area Maps and Shapefiles. Available at http://wgfd.wyo.gov/web2011/wildlife-1000382.aspx. Accessed Sept. 10, 2010.

Wyoming Interagency Vegetation Committee, 2002, Wyoming Guidelines for Managing Sagebrush Communities with Emphasis on Fire Management, Wyoming Game and Fish Department and Wyoming BLM, Cheyenne, WY. 


\begin{abstract}
APPENDIX
MAPS OF SEASONAL SAGE-GROUSE DISTRIBUTIONS PROJECTED UNDER BASELINE CONDITIONS AND DEVELOPMENT SCENARIOS BEFORE, DURING, AND AFTER DEVELOPMENT
\end{abstract}



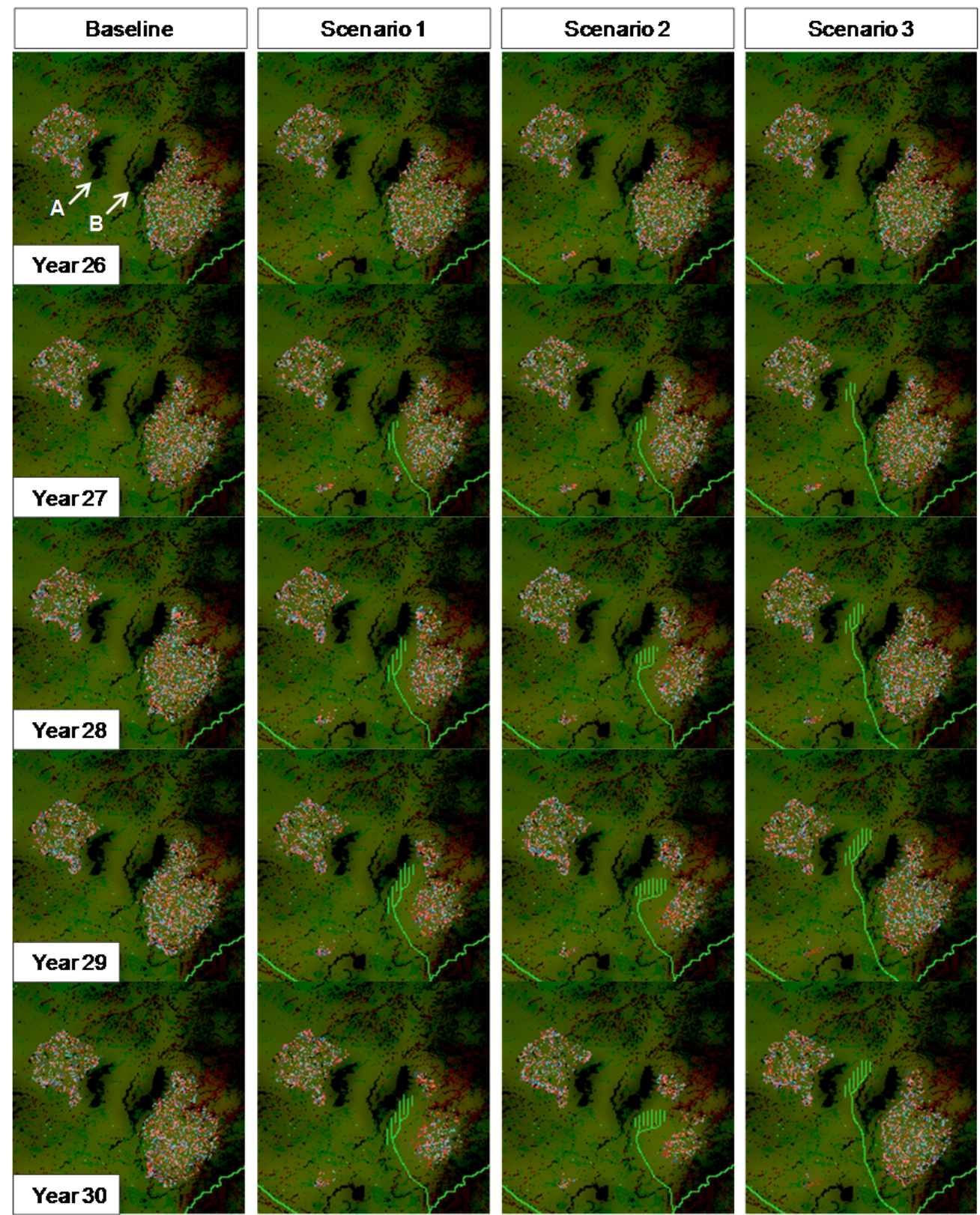
4 Wind turbine and roads
-Wells
A Male adult
A Female adut
$\Delta$ Male juvenile
- Fernale juvenile
A Male yearling
Female yearling

FIGURE A-1 Modeled Spatial Distribution of Sage-Grouse Population in Winter under Baseline Condition (no development) and Three Hypothetical Development Scenarios over 5 Years (a year before, during, and a year after the development) (Wheatland Reservoir Number 3 [A] and Wheatland Reservoir Number 2 [B] are indicated in the Year 26 baseline map for geographic reference.) 

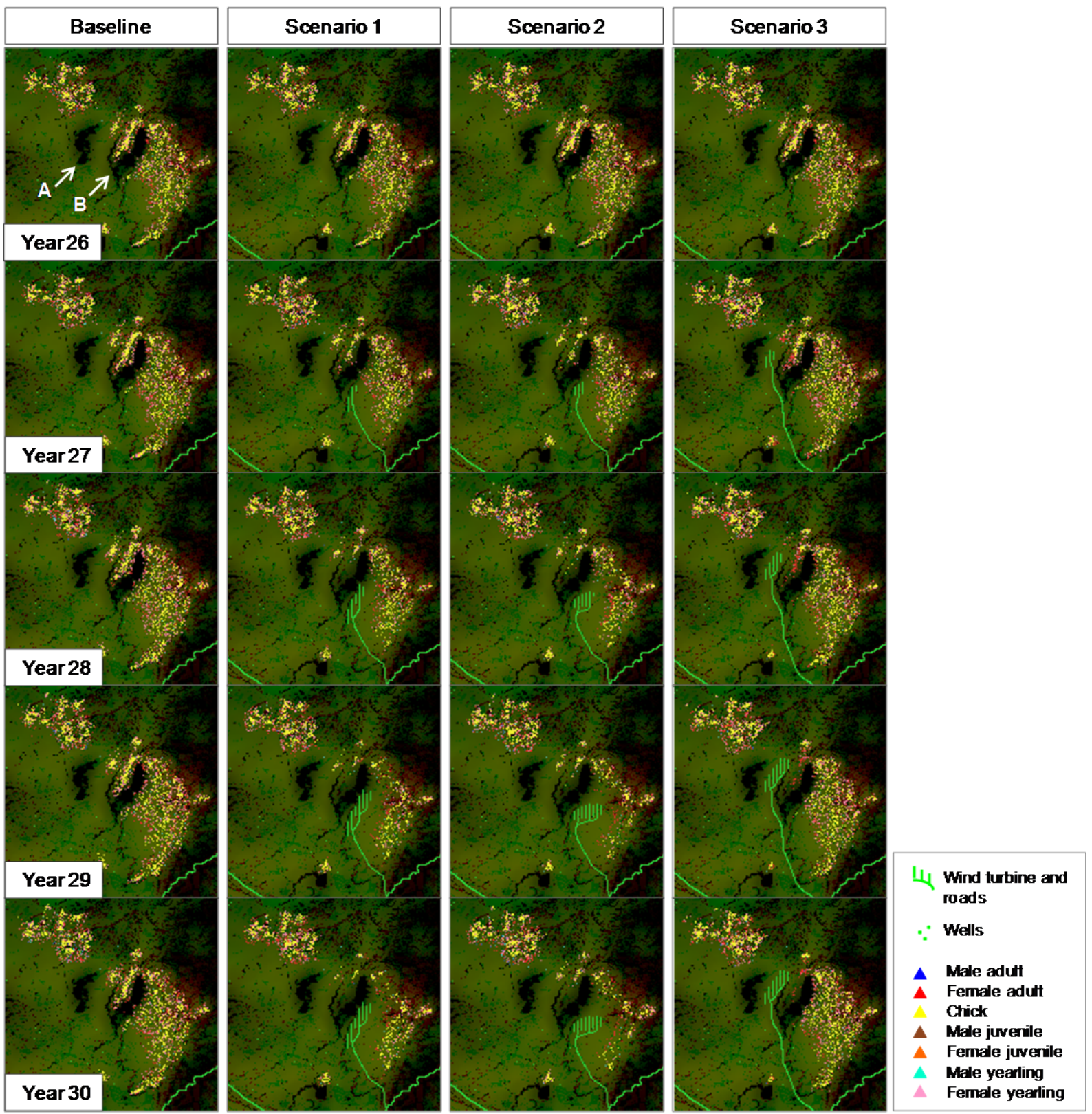

FIGURE A-2 Modeled Spatial Distribution of Sage-Grouse Population in Spring (after the Lekking Season) under Baseline Condition (no development) and Three Hypothetical Development Scenarios over 5 Years (a year before, during, and a year after the development) (Wheatland Reservoir Number 3 [A] and Wheatland Reservoir Number 2 [B] are indicated in the Year 26 baseline map for geographic reference.) 

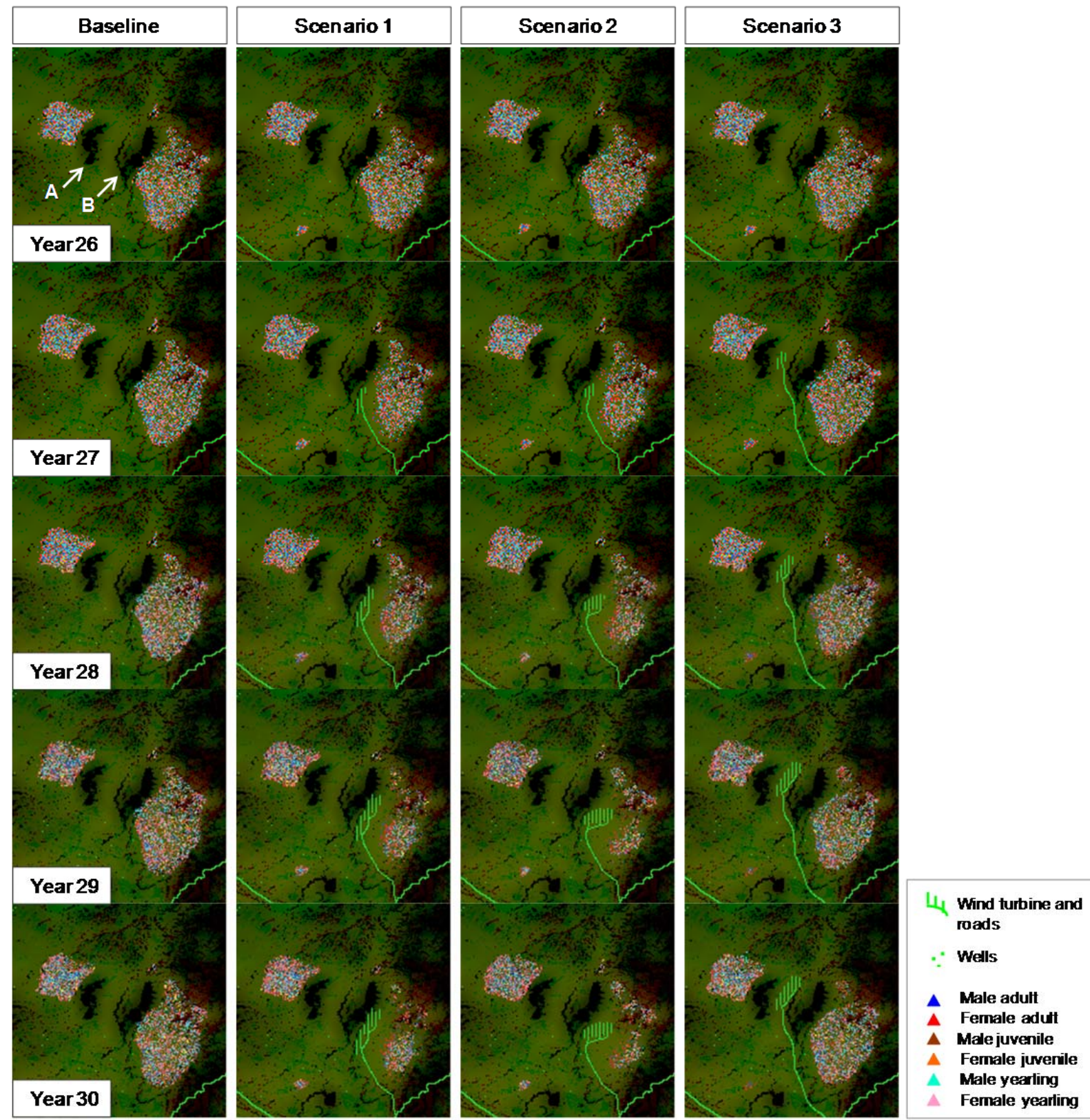

FIGURE A-3 Modeled Spatial Distribution of Sage-Grouse Population in Summer under Baseline Condition (no development) and Three Hypothetical Development Scenarios over 5 Years (a year before, during, and a year after the development) (Wheatland Reservoir Number 3 [A] and Wheatland Reservoir Number 2 [B] are indicated in the Year 26 baseline map for geographic reference.) 


\section{Argonne}

\section{Environmental Science Division}

Argonne National Laboratory

9700 South Cass Avenue, Bldg. 240

Argonne, IL 60439

www.anl.gov 